Post-print version of the article published in J.Phys.Chem.C 121, 23839 (2017)

\title{
Role of Ethanolamine on the Stability of a Sol- Gel ZnO Ink
}

\author{
A. Gómez-Núñez ${ }^{1}$, S. Alonso-Gil' ${ }^{2}$ C. López ${ }^{2}$, P. Roura ${ }^{3}$ and A. Vilà ${ }^{1 *}$ \\ ${ }^{1}$ Department of Engineering: Electronics, University of Barcelona, Martí i Franquès 1, E-08028- \\ Barcelona, Spain. Institute of Nanoscience and Nanotechnology (IN2UB), University of \\ Barcelona, Joan XXIII s/n, E-08028-Barcelona, Spain. avila@el.ub.edu \\ ${ }^{2}$ Department of Inorganic and Organic Chemistry, University of Barcelona, Martí i Franquès 1, \\ E-08028-Barcelona, Spain. \\ ${ }^{3}$ Department of Physics, University of Girona, Campus Montilivi, Edif. PII, E-17003-Girona, \\ Spain.
}

Abstract: This work presents a detailed structural and chemical characterization of the system formed by zinc acetate dihydrate (ZAD) and ethanolamine (EA) with methoxyethanol (ME), in order to describe its stability. The origin of the mixture degradation during storage at room conditions is analyzed. Theoretical calculations of the frontier orbitals of the system ZAD plus EA under interaction with $\mathrm{ME}$ and $\mathrm{CO}_{2}$ are used to deduce energy levels and stability of the different molecules appearing in the ZAD-EA-ME system. The models were tested as potential energy minimum and their photo-absorption spectra were simulated. The dimerization process leading from the simplest configuration to the most abundant one is also theoretically analyzed and used to describe the effect of the nuclearity raise on the mixture stability. Our results explain the experimental observations and provide a better understanding of the role played by $\mathrm{EA}$ in the formation of $\mathrm{ZnO}$ and, consequently, allow optimizing the technological processes to prepare these films.

\section{INTRODUCTION}

An optimal sol-gel precursor design is a key point for the emerging flexible and printed electronics development. Nowadays, sol-gel-derived $\mathrm{ZnO}$ is one of the most attractive oxides, due to its high electrical conductivity ${ }^{1}$, good ultraviolet absorption behaviour, strong room- 
temperature luminescence ${ }^{2}$, piezoelectricity, excellent environmental stability, chemical sensing ${ }^{3}$, compatibility with large-scale processing, low cost, abundance, biocompatibility and easy fabrication. In most reports published so $\mathrm{far}^{4}$, it is obtained by using zinc acetate dihydrate (ZAD) as salt and ethanolamine (EA) as stabilizer. The increasing interest in the development of sol-gel $\mathrm{ZnO}$ inks is reflected by recent specific studies on the effect of solvents $^{5,6}$, precursor nature and concentration ${ }^{7,8}$, EA:ZAD molar ratios ${ }^{9,10}$, sol ageing ${ }^{11}$, annealing duration ${ }^{12,13}$, annealing temperature ${ }^{14,15}$, and even specific process parameters such as withdrawal speed in deep coating ${ }^{16}$ on the properties of the resulting $\mathrm{ZnO}$.

Stabilization of the $\mathrm{Zn}(\mathrm{II})$ ion is crucial in sol-gel processes to obtain high quality $\mathrm{ZnO}$ films. Most of the inks reported to date involve the use of aminoalcohols as stabilizers. However, rigid aminoalcohols such as $\mathrm{H}_{2} \mathrm{~N}-\mathrm{C}_{6} \mathrm{H}_{4}-2 \mathrm{R}$ with $\mathrm{R}=\mathrm{OH}$ or $\mathrm{CH}_{2} \mathrm{OH}$ are not adequate ${ }^{17}$ because of the fast degradation of the formed precursors even at room temperature, which precludes their use for $\mathrm{ZnO}$ preparation. Indeed, it is known that aminoalcohols present high photosensitivity: radicals based on $\mathrm{CH}_{3}-\mathrm{OCH}_{2}$ are formed after UV-irradiation ${ }^{18}$ and photooxidative cyclization of aminoalcohols produce 1,3-oxazines ${ }^{19}$. In consequence, the photosensitivity observed in the $\mathrm{ZnO}$ precursors containing aminoalcohols is a major issue in order to avoid degradation during ink storage.

EA is by far the preferred aminoalcohol to stabilize the $\mathrm{Zn}(\mathrm{II})$, but it does not escape from the previous observation. It is known that EA facilitates $\mathrm{Zn}$ (II) chelation and promotes the formation of $\mathrm{ZnO}$ due to the amine functional group that increases the solution $\mathrm{pH}^{20}$. Consequently, a higher amount of EA leads to higher chelation rates of $\mathrm{Zn}^{2+}$ ions along the (002) minimum-surface-energy plane, resulting in higher $c$-axis orientation with less porosity ${ }^{10}$. In particular, processes such as hydrolysis, polymerization and complexation have been identified to notably influence the structure and rate of the crystallization ${ }^{21}$. Nevertheless, the presence of ethanolamine on the top of $\mathrm{ZnO}$ thin films significantly decreases the optical performance of $\mathrm{ZnO}$ devices ${ }^{20}$ and, in general, amines cause a dramatic impact on the optoelectronic properties and morphology of the $\mathrm{ZnO}$ films by degrading sol transparency and stability $^{22}$. Therefore, the technology to obtain $\mathrm{ZnO}$ thin films from sol-gel process is not definitively controlled yet and requires further investigation.

This paper presents a detailed analysis of the origin of the ink (ZAD+EA+ME) degradation during storage at room conditions. After an introduction to the materials and methods, the experimental results are correlated with Density Functional Theory (DFT), which is known to be a useful and powerful tool to understand the evolution of many organic molecules, condensed 
substances and even metal organic complexes. A final calculation allows describing in detail the equilibrium between the two most important forms, since, as already shown ${ }^{23}$, the reaction of EA with ZAD produces tetramers ([Zn $]_{4}$, Figure 1$)$ that are not stable in solution. Our results provide a better understanding of the ink degradation and, consequently, allow optimizing the technological processes to prepare precursors, in order to obtain good $\mathrm{ZnO}$ films ${ }^{24}$.

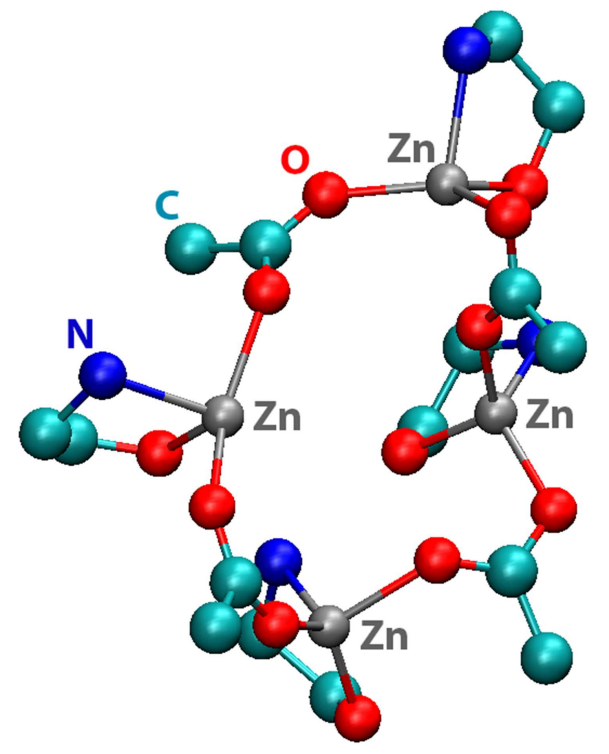

Figure 1. Schematic view of the core of the tetramer $[\mathrm{Zn}]_{4}$ formed after the interaction between $\mathrm{ZAD}, \mathrm{EA}$ in ME ( $\mathrm{H}$ atoms have been omitted for clarity), where $\mathrm{Zn}(\mathrm{II})$ atoms are simultaneously bound to two bridging-acetate and one bidentate-(N,O)- EA ligands.

\section{EXPERIMENTAL}

\section{Materials and procedures}

The $\mathrm{ZnO}$ precursor was prepared by stabilizing zinc acetate dihydrate $\left(\mathrm{Zn}\left(\mathrm{CH}_{3} \mathrm{COO}\right)_{2} \cdot 2 \mathrm{H}_{2} \mathrm{O}\right.$, ZAD, from Panreac) with ethanolamine $\left(\mathrm{H}_{2} \mathrm{NCH}_{2} \mathrm{CH}_{2} \mathrm{OH}\right.$, EA, from Acrös Organics). Then, 2methoxyethanol $\left(\mathrm{CH}_{3} \mathrm{O}\left(\mathrm{CH}_{2}\right)_{2} \mathrm{OH}, \mathrm{ME}\right.$, from Aldrich) was added as a solvent to prepare the ink, following the method reported in previous work ${ }^{23}$. Some of these mixtures were stored at various room conditions for some weeks, showing evidences of chemical degradation. Sensitivity to light was tested by leaving the samples over the lab desk. 
${ }^{1} \mathrm{H}$ Nuclear Magnetic Resonance (NMR) studies were performed at $298 \mathrm{~K}$ in a Mercury-400 $\mathrm{MHz}$ instrument, using MeOD (99.9\%) as solvent. Complementary Evolved Gas Analysis (EGA) was performed in vacuum with a heating rate of $20 \mathrm{~K} / \mathrm{min}$ using a MKS quadrupole mass spectrometer (Microvision Plus).

\section{Quantum mechanical simulations}

To elucidate the effect of light, $\mathrm{CO}_{2}$ and $\mathrm{ME}$ on the stability of the reagents and the precursor, the energy levels and stability of the different molecules appearing in the ZAD-EAME system were deduced from quantum mechanical simulations. Ten molecular models were defined for Time-Dependent Density Functional Theory (TD-DFT) simulations: the isolated EA, monomer $[\mathrm{Zn}]_{1}$ and dimer $[\mathrm{Zn}]_{2}$ (see Figure 2 ); these three models solvated with implicit $\mathrm{ME}[\varepsilon$ $=17.2]$; and $[\mathrm{Zn}]_{1}$ and $[\mathrm{Zn}]_{2}$ with one and two $\mathrm{CO}_{2}$ molecules, respectively, before and after solvation.

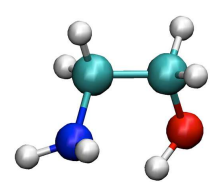

EA

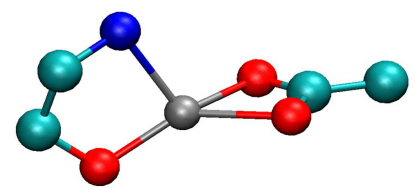

$[\mathrm{Zn}]_{1}$

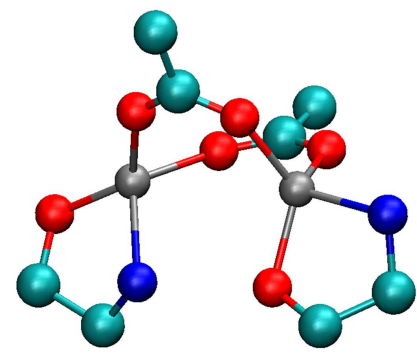

$[\mathrm{Zn}]_{2}$

Figure 2. Ethanolamine, monomer $[\mathrm{Zn}]_{1}$ and dimer $[\mathrm{Zn}]_{2}$ models according to the structures optimized in ${ }^{23}$. The $\mathrm{H}$ atoms in $[\mathrm{Zn}]_{1}$ and $[\mathrm{Zn}]_{2}$ are not represented for clarity.

All these models were optimized by means of the Gaussian 03 software ${ }^{25}$ and the UB3LYP hybrid method ${ }^{26,27}$ using the LANLD2Z basis set ${ }^{28,29}$ with a threshold of $10^{-7}$ a.u. in the potential energy and $10^{-5}$ a.u. in the maximum nuclear force component (see the optimized atomic coordinates in Tables S1-S10). The implicit solvent models were performed using the Polarizable Continuum Model (PCM) via a set of overlapping spheres ${ }^{30}$. Moreover, the models were tested as potential energy minimum and their photo-absorption spectra were simulated using the Time-Dependent DFT approach ${ }^{31,32}$ (see the Supplementary information for mathematical details). 
For the simulations of the dimerization process, a new isolated model of a bimolecular $2[\mathrm{Zn}]_{1}$ system was reconstructed by forcing the hydrogen-bond interaction between every $\mathrm{N}-$ $\mathrm{H} \cdots \mathrm{O}_{\mathrm{AcO}}$ pair (Figure 3 ) by means of Gaussian 03 and using the previously mentioned DFT method and basis set. From this structure, the potential free energy surface (PES) of the dimerization process was generated by using the relaxed scan methodology over two catalytic variables. In total, 121 structures $(11 \times 11$ changing each variable around the starting values of $\mathrm{d} 1=4.03 \AA$ and $\mathrm{d} 2=3.94 \AA$ ) were optimized to calculate the PES and to predict the Minimum Potential Energy Pathway (MPEP) followed by the system.

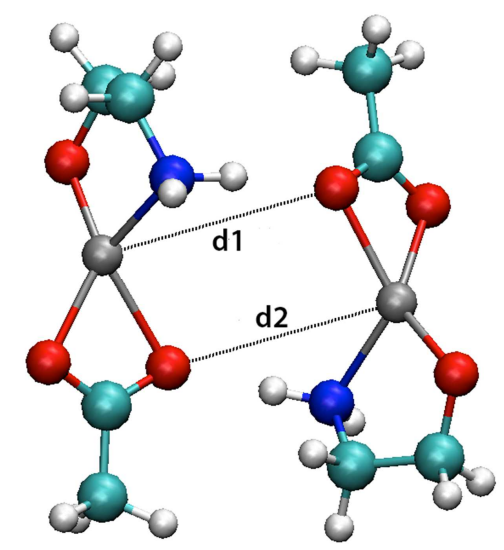

Figure 3. The bimolecular $2[\mathrm{Zn}]_{1}$ system reconstructed by changing the distances $\mathrm{d} 1$ and $\mathrm{d} 2$ around their respective equilibrium values.

\section{RESULTS AND DISCUSSION}

\section{Stability of EA with ME and ZAD under different conditions}

Several experiments were carried out in order to compare the stability of the freshly prepared ink $(E A+Z A D+M E)$ with those of the free ethanolamine $(E A)$ and $E A$ in 2methoxyethanol $(E A+M E)$. In a first step, the samples were kept under illumination but avoiding the contact with air. After 4 weeks, no modification was apparent in any of the samples (Figure 4a).

Next, the samples were exposed to the action of air by uncovering the flasks. Figs. $4 \mathrm{~b}$ to $4 \mathrm{e}$ show the evolution of the appearance of the samples after 2, 4, 6 and 8 weeks in contact with air under illumination. A slight change in the aspect of EA and EA+ME+ZAD was detected during the first 3 weeks, while EA+ME remained colourless and transparent (Figure 4b). This observation indicates that this ink is clearly more stable than those containing more rigid 
aminoalcohols ${ }^{17}$ already mentioned in the Introduction because, in the presence of ZAD and $M E$, these produce black suspensions in a few minutes (if $\mathrm{R}=\mathrm{OH}$ ) or hours (if $\mathrm{R}=\mathrm{CH}_{2} \mathrm{OH}$ ) at room conditions.

At the fourth week, the ink became cloudy and precipitated, while EA and EA+ME turned yellowish and orange, respectively, suggesting that some chemical transformation was taking place. As shown in Figures $4 c$ to $4 e$, the colour change is more apparent in $E A+M E$, thus indicating that the solvent ME plays a role in this process and perhaps determines the nature of the products. Although some degradation by light may have occurred before the flasks were uncovered, degradation was only visible when the samples were kept in contact with air.

To assess how important was light excitation in these degradation processes, in a third experiment fresh samples were kept uncovered in the dark. After 4 weeks, the appearance of $E A$ and EA+ME was similar to that observed in the previous experiment, while the complete ink showed less precipitate. Consequently, the presence of light mainly affects the sample containing Zn.

In summary, these experiments demonstrate that the degradation of all three samples is mainly due to reaction with some species contained in air, with a minor influence of light excitation in the ink degradation. The following experiments are thus focused on identifying the reacting species through the degradation products.

a)

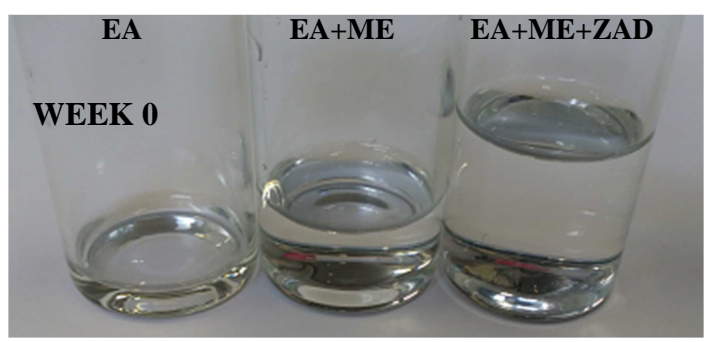

b)

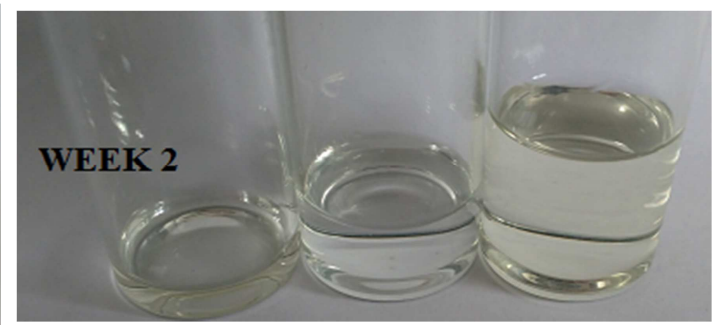


c)

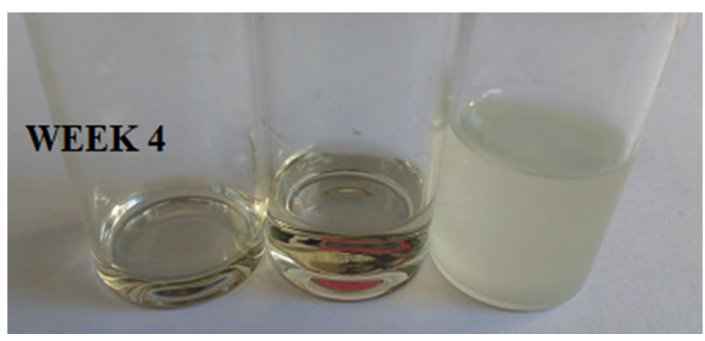

d)

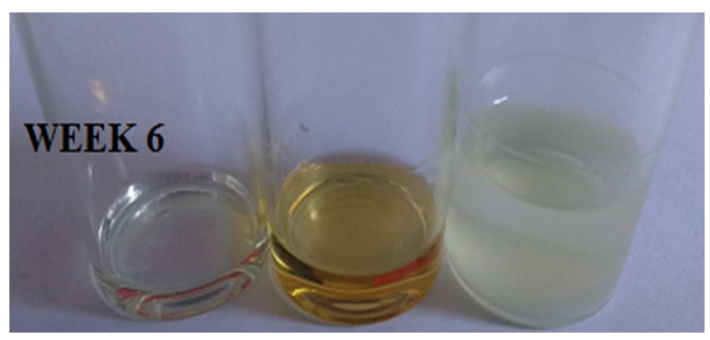

e)

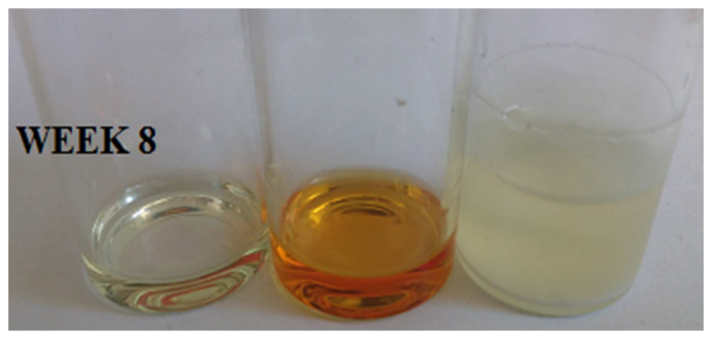

Figure 4. Pictures of EA (left), EA dissolved in $M E$ (centre) and the ZAD+EA+ME ink (right). Freshly prepared (a) and after 2 (b), 4 (c), 6 (d) and 8 (e) weeks of storage at room temperature in contact with air and under illumination.

A ${ }^{1} \mathrm{H}-\mathrm{NMR}$ experiment was performed for the 8-weeks degraded EA+ME sample (at the centre in Figure 4e), to find out the degradation products. MeOD was used as solvent for NMR, owing to the low solubility of the mixture. During specimen preparation, the deep orange colour of EA+ME fainted giving a pale-yellow solution. This could be ascribed a) to the different polarity of the solvent (MeOD, $\left.\mu_{D}=3.09 \mathrm{D}\right)$ and $\mathrm{ME}\left(\mu_{\mathrm{D}}=2.14 \mathrm{D}\right)$, or $\left.\mathrm{b}\right)$ to their ability to establish intermolecular hydrogen-bond contacts with the species in solution.

The H-NMR spectrum (Figure S1, supporting information) suggests the coexistence of several species in solution, as several singlets were detected in the range $6.8-8.5 \mathrm{ppm}$. Their positions are compatible with the presence of protons bound to $\mathrm{N}$ atoms attached to - $\mathrm{CO}$ or COO arrays, as the carbamic acids, zwitterions and carbamates (see Scheme 1) recently proposed by Kortunov ${ }^{33}$ when amines and aminoalcohols capture $\mathrm{CO}_{2}$. The nature of the final products and their relative abundance are described to depend on a wide variety factors such as temperature, amine or aminoalcohol concentration, solvent nature (specially its polarity 
and its tendency to establish hydrogen bonds), and $\mathrm{CO}_{2}$ partial. In turn, these complexes have been reported to react with $-\mathrm{OH}$ groups and form several lactams and lactims with different colouration $^{34,35}$. and the $\mathrm{pH}$ (and thus the presence of $\mathrm{ME}$ and MeOD) seems to influence the tautomer ratio between them ${ }^{36-37}$.

Hence, these observations suggest that ME promotes EA degradation even at room temperature, while the precursor formed when $Z A D$ is added to the EA+ME mixture ${ }^{23}$ contains deprotonated EA which acts as an $(\mathrm{N}, \mathrm{O})^{-}$bidentate ligand that might stabilize EA. The reactions proposed in Scheme 1 can explain the observed colours, as well as the presence (or coexistence) of several compounds with - $\mathrm{NHC}(\mathrm{O})$ - functional groups detected by NMR in $\mathrm{EA}+\mathrm{ME}$ after long storage periods. Consequently, capture of both $\mathrm{CO}_{2}$ and $-\mathrm{OH}$ seems demonstrated.

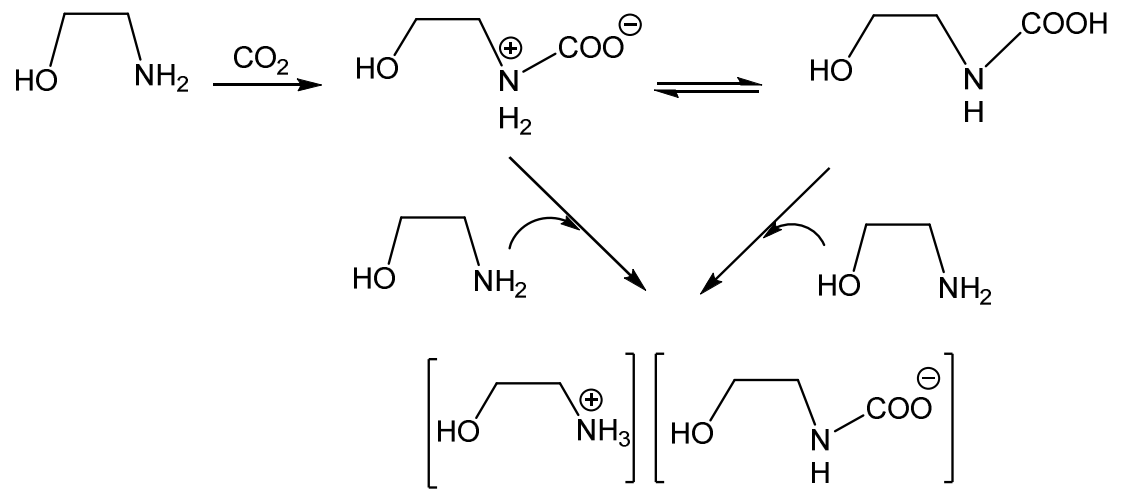

Scheme 1. Degradation mechanism proposed for EA in the presence of $\mathrm{CO}_{2}$. Next reaction with $-\mathrm{OH}$ would give lactams or lactims.

As a complementary experiment, Evolved Gas Analysis was used to elucidate the composition of the samples before and after degradation under illumination in air. A variety of mass fragments from $\mathrm{m} / \mathrm{z}=12$ to 86 was detected from the inks, and their respective EGA curves were classified according to their dependence on temperature ${ }^{24,38}$. In particular, the group related with $m / z=76$ (Figure $5 a$ ) can be associated with some non-bonded and degraded EA decomposition fragments ${ }^{39}$. Our previous results support this possibility, since some carbamate groups (with $m / z=76$ ) have been detected by NMR at room temperature (Scheme 1).

To confirm this hypothesis, the degraded samples were also measured by EGA. The peak patterns obtained in this case were similar to the non-degraded ones, but the $m / z=76$ EGA signal appeared to be much more intense. As shown in Figure $5 b$, the degraded EA+ME 
presents an $m / z=76$ peak which is one order of magnitude more intense than the one in Figure $5 \mathrm{a}$ (as indicated by the multiplication factors in both graphs), suggesting a more relevant presence of carbamates (as no ME was added) as compared to deprotonated EA $(\mathrm{m} / \mathrm{z}$ $=60$ ) and the other fragments.
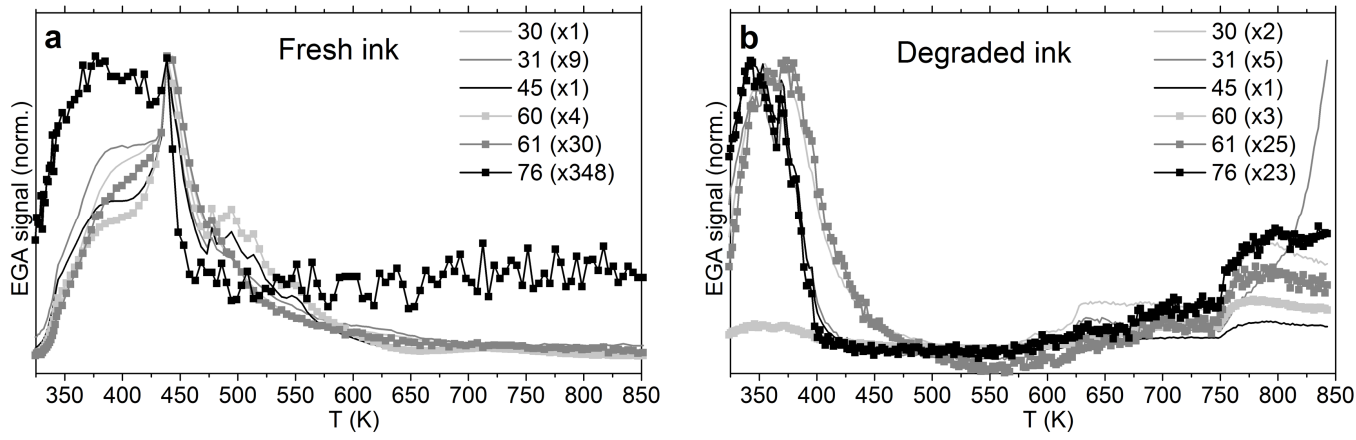

Figure 5. Normalized EGA signals of compounds related to $m / z=76$ for freshly-prepared $E A+M E+Z A D(a)$ and $E A+M E$ after 8-weeks degradation in air and light (b), with their respective normalization factors in parenthesis.

Consequently, after degradation there is less EA while one of the degradation products $(\mathrm{m} / \mathrm{z}$ $=76$, scheme 1) has clearly increased. Mass spectrometry of EGA can thus provide not only qualitative but also quantitative clues of the ink degradation at room temperature by means of the $m / z=76$ vs. $m / z=60$ ratio.

\section{Time-Dependent Density Functional Theory, TD-DFT, calculations}

These experimental results support the proposed reaction mechanism (Scheme 1). However, it is still not clear what prevents EA and EA+ME to degrade more under illumination, while the complete ink does. In order to understand the influence of external factors -such as exposition to light or air- on the mixtures stability and their tendency to react, computational studies based on TD-DFT and Molecular Orbital (MO) calculations were undertaken.

For comparison purposes, an initial study of EA both in vacuum and in ME was carried out. The results, summarized in Figure 6 and Table 1, revealed that:

i) the HOMO-LUMO gap energy is high (> $8.5 \mathrm{eV})$ in both cases;

ii) the first absorption bands involve mainly the electronic HOMO $\rightarrow$ LUMO transition; and 
iii) in ME, these bands shift to higher energies and the weight of the HOMO --> LUMO transition increases as well as its oscillator strength, indicating a higher tendency of this transition to occur.

Moreover, the contribution of the nitrogen $2 p_{z}$ orbital in the HOMO of EA+ME is higher than for the isolated aminoalcohol (see Figure 6). This indicates that it becomes more nucleophilic, and therefore more prone to react with $\mathrm{CO}_{2}$. This is consistent with the faster degradation of $E A+M E$ during storage in air.
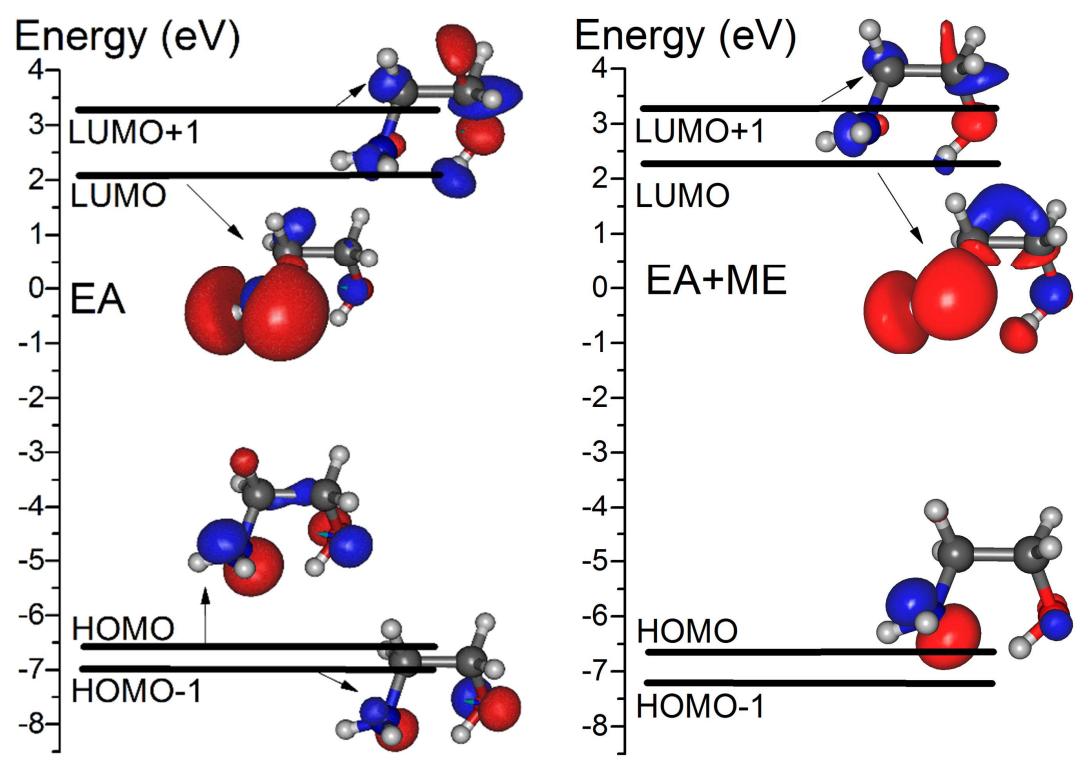

Figure 6. Frontier orbitals calculated with Gaussian for EA and EA+ME. Different close energy levels with similar orbital scheme (as HOMO and HOMO-1 in EA+ME) are not marked with arrows.

\begin{tabular}{|c|c|c|c|}
\hline \multicolumn{3}{|c|}{ EA } \\
\hline $\boldsymbol{\lambda} \mathbf{( n m )}$ & Assignment & Oscill. Str. & Wt. (\%) \\
\hline \multirow{2}{*}{184.0} & HOMO-1 $\rightarrow$ LUMO & -0.287 & 16 \\
& HOMO $\rightarrow$ LUMO & -0.638 & 81 \\
\hline \multirow{2}{*}{167.9} & HOMO $\rightarrow$ LUMO & 0.683 & 93 \\
\hline \multirow{2}{*}{246.8} & HOMO-1 $\rightarrow$ LUMO & 0.524 & 55 \\
& HOMO $\rightarrow$ LUMO+1 & 0.281 & 16 \\
\hline
\end{tabular}

\begin{tabular}{|c|c|c|c|}
\hline \multicolumn{4}{|c|}{ EA + ME } \\
\hline $\boldsymbol{\lambda}(\mathbf{n m})$ & Assigment & Oscill. Str. & Wt. (\%) \\
\hline 176.3 & HOMO $\rightarrow$ LUMO & 0.687 & 94 \\
\hline 162.0 & HOMO $\rightarrow$ LUMO & 0.701 & 98 \\
\hline
\end{tabular}


Table 1. Excitation wavelengths $(\lambda)$ with their respective assignments, oscillation strengths and probability weights, calculated by TD-DFT for EA and EA+ME.

Keeping these results in mind, the influence of $\mathrm{CO}_{2}, \mathrm{ME}$ and nuclearity on the stability of the system with $\mathrm{Zn}$ at room conditions was analyzed. Since $[\mathrm{Zn}]_{4}$ seems only stable in crystals ${ }^{23}$, and in solution $[\mathrm{Zn}]_{4}$ evolves to produce the monomer $[\mathrm{Zn}]_{1}$ and the dimer $[\mathrm{Zn}]_{2}$, we will skip the tetramer simulation in this study and compare the results of $[\mathrm{Zn}]_{1}$ and $[\mathrm{Zn}]_{2}$ to infer the influence of the nuclearity on the system stability.

The HOMOs and LUMOs of $[\mathrm{Zn}]_{1}$ and $[\mathrm{Zn}]_{2}$ (Figure 7) are markedly different from those of EA and EA+ME (Figure 6). In these $\mathrm{Zn}(\mathrm{II})$ complexes, HOMO is concentrated on the $2 p_{z}$ orbital of the deprotonated oxygen instead of the nitrogen atom of EA. So, it is the $\mathrm{O}$ and not the $\mathrm{N}$ atom that will react with $\mathrm{CO}_{2}$. Besides, in $[\mathrm{Zn}]_{1}$, the LUMO is basically $\mathrm{Zn}(\mathrm{II})$ centred, while for $[\mathrm{Zn}]_{2}$ it is mainly located on the donor atoms of the two bridging ligands (Figure 7). Concerning the HOMO-LUMO gap, its value (5.7 eV for $[\mathrm{Zn}]_{1}$ and $4.7 \mathrm{eV}$ for $\left.[\mathrm{Zn}]_{2}\right)$ decreases considerably in relation to EA without $\mathrm{Zn}$ compounds (> $8.5 \mathrm{eV})$.

When considering the contact with $\mathrm{ME}$, the energy required for the first electronic transition is smaller -and closer to the visible region- for $[\mathrm{Zn}]_{2}+\mathrm{ME}$ than for $[\mathrm{Zn}]_{1}+\mathrm{ME}$ (Table 2) thus suggesting that the dimer is more prone to undergo a photoexcitation than $[\mathrm{Zn}]_{1}$.

$\mathrm{CO}_{2}$ affects significantly the frontier orbitals of both $[\mathrm{Zn}]_{1}$ and $[\mathrm{Zn}]_{2}$, mainly the LUMO. In particular, for $[\mathrm{Zn}]_{2}+\mathrm{CO}_{2}$, (Figure 7 and Table 2) the LUMO is mainly a $\pi^{*}$ orbital of the bidentate $\mathrm{AcO}^{-}$ligand, while it is basically $\mathrm{Zn}(\mathrm{II})$ centred when the calculations are performed for vacuum or in ME. Moreover, the contribution of the atoms of the bridging ligands and EA's $\mathrm{N}$ is also modified for $[\mathrm{Zn}]_{2}+\mathrm{CO}_{2}$. Thus, carbon dioxide will react not only with the excited state but it will act as an assistant during photoexcitation, leading to a destabilization of the precursor. Also, in contrast with the presence of $\mathrm{ME}$, the increase of nuclearity and the presence of $\mathrm{CO}_{2}$ makes increase the wavelength towards the visible range and its transition probability.

Finally, the combined presence of both $\mathrm{ME}$ and $\mathrm{CO}_{2}$ does not change significantly the excitation wavelengths and probability weights of the monomer. On the contrary, for $[\mathrm{Zn}]_{2}, \mathrm{TD}$ DFT calculations suggest that ME slightly reduces these two parameters independently of the presence of $\mathrm{CO}_{2}$. Therefore, the dimer is found to be sensitive to $\mathrm{ME}$ and $\mathrm{CO}_{2}$, but, when both are present, ME seems to dominate. 
In summary, these TD-DFT calculations have proved that:

i) $\quad \mathrm{ME}$ and $\mathrm{CO}_{2}$ induce significant and relevant changes on the properties and reactivity of both $[\mathrm{Zn}]_{1}$ and $[\mathrm{Zn}]_{2}$, and

ii) the dimer is expected to be more reactive and photosensitive than the monomer. 


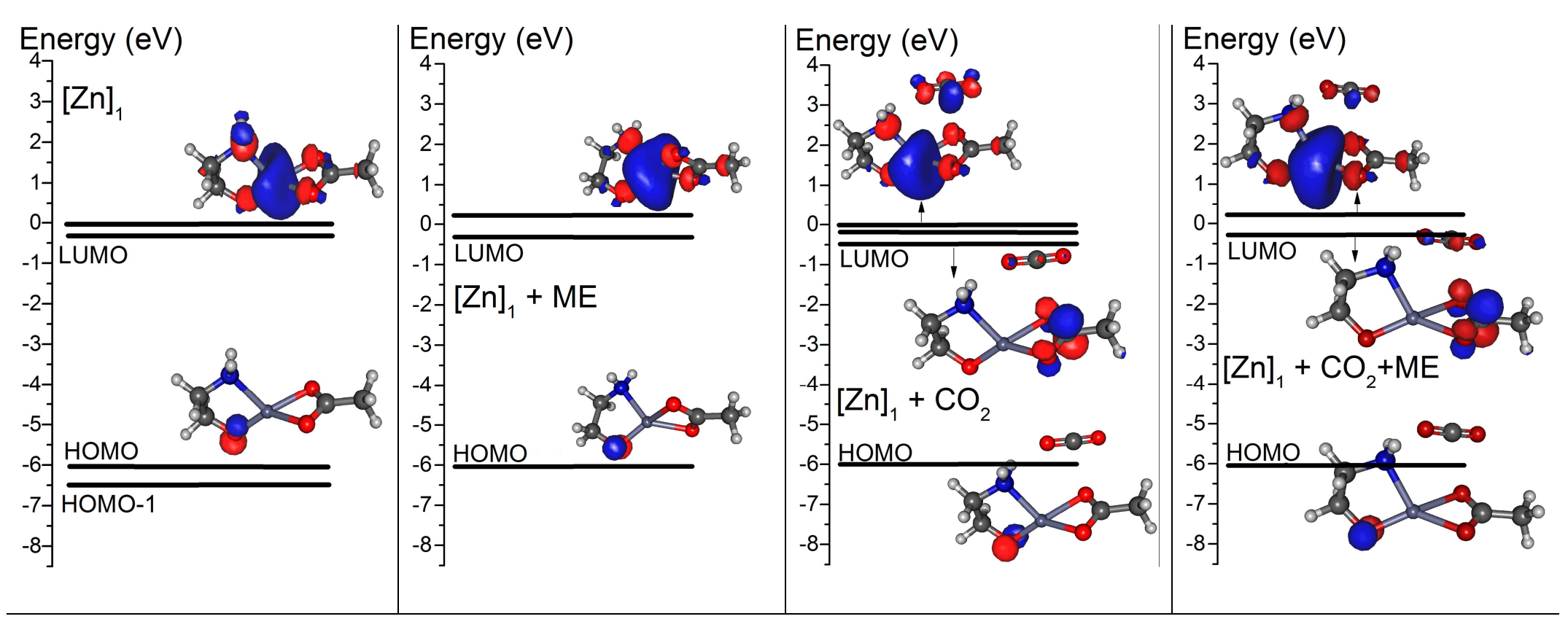



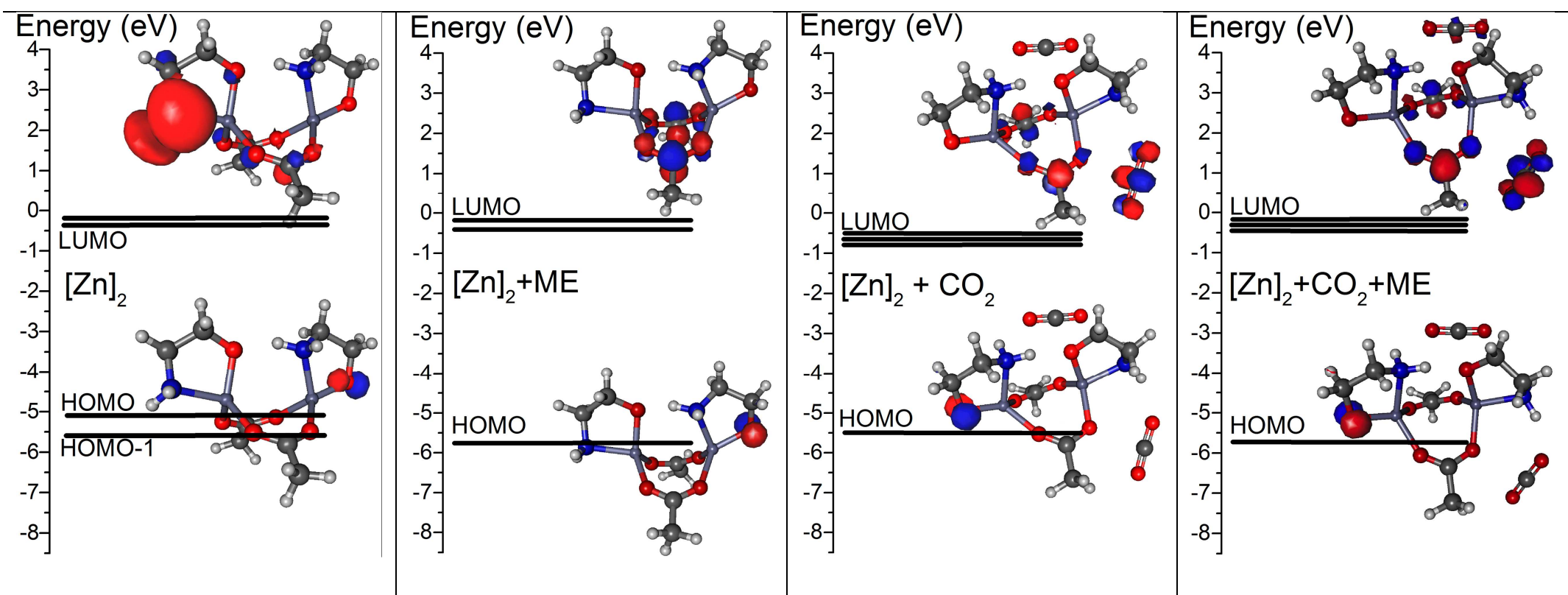

Figure 7. Frontier orbitals $\mathrm{HOMO}$ and LUMO of the systems: $[\mathrm{Zn}]_{1}$ (top) and $[\mathrm{Zn}]_{2}$ (bottom), in vacuum and in presence of $\mathrm{ME}, \mathrm{CO}_{2}$ and both.

\begin{tabular}{|c|c|c|c|c|}
\hline \multirow{4}{*}[]{$^{*}$} & $\boldsymbol{\lambda}(\mathbf{n m})$ & Assigment & Oscill.Str. & Wt. (\%) \\
\cline { 2 - 5 } & 269.1 & HOMO $\rightarrow$ LUMO+1 & 0.617 & 76 \\
\cline { 2 - 5 } & \multirow{2}{*}{252.6} & HOMO $\rightarrow$ LUMO & -0.380 & 29 \\
& & HOMO $\rightarrow$ LUMO+1 & 0.587 & 69 \\
\cline { 2 - 5 } & \multirow{2}{*}{246.8} & HOMO-1 $\rightarrow$ LUMO & -0.326 & 21 \\
& & HOMO-1 $\rightarrow$ LUMO+1 & 0.602 & 73 \\
\hline
\end{tabular}

\begin{tabular}{|c|c|c|c|c|}
\hline \multirow{4}{*}{$\mathbf{Z n}_{2}$} & $\boldsymbol{\lambda}(\mathbf{n m})$ & Assignment & Oscill.Str. & $\mathbf{W t .}(\%)$ \\
\cline { 2 - 5 } & 303.6 & HOMO $\rightarrow$ LUMO & 0.704 & 99 \\
\cline { 2 - 5 } & 302.9 & HOMO $\rightarrow$ LUMO & 0.706 & 100 \\
\cline { 2 - 5 } & 286.3 & HOMO $\rightarrow$ LUMO+1 & 0.330 & 22 \\
\hline
\end{tabular}

\begin{tabular}{|c|c|c|c|c|}
\hline \multirow{2}{*}[\mathbf{Zn}]{$_{1}+\mathrm{ME}$} & $\boldsymbol{\lambda}(\mathbf{n m})$ & Assignment & Oscill.Str. & Wt. (\%) \\
\cline { 2 - 5 } & \multirow{2}{*}{247.6} & $\mathrm{HOMO} \rightarrow$ LUMO & -0.416 & 35 \\
& & HOMO $\rightarrow$ LUMO +1 & 0.544 & 59 \\
\cline { 5 - 6 } & &
\end{tabular}

\begin{tabular}{|c|c|c|c|c|}
\hline \multirow{4}{*}[\mathbf{Zn}]{$_{2}+$ ME } & $\boldsymbol{\lambda}(\mathbf{n m})$ & Assignment & Oscill.Str. & Wt. (\%) \\
\cline { 2 - 5 } & 264.2 & HOMO $\rightarrow$ LUMO & -0.689 & 95 \\
\cline { 2 - 5 } & 263.0 & HOMO $\rightarrow$ LUMO & 0.705 & 99 \\
\hline
\end{tabular}




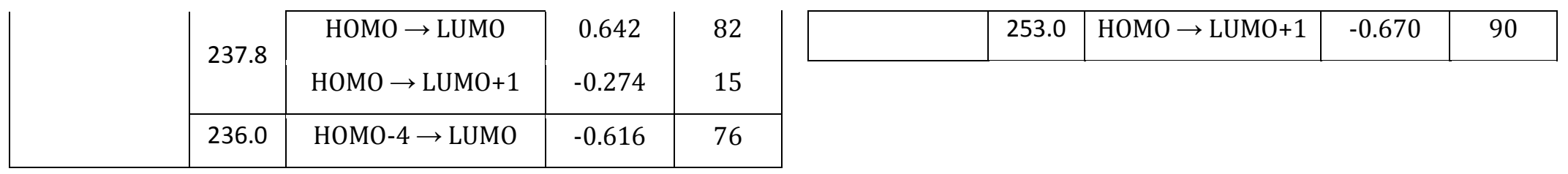

\begin{tabular}{|c|c|c|c|c|}
\hline & $\boldsymbol{\lambda}(\mathbf{n m})$ & Assignment & Oscill.Str. & Wt. (\%) \\
\cline { 2 - 5 } & \multirow{3}{*}{271.5} & HOMO $\rightarrow$ LUMO+2 & 0.275 & 15 \\
& & HOMO $\rightarrow$ LUMO+3 & 0.58468 & 68 \\
\cline { 2 - 5 }$+\mathbf{C O}_{2}$ & \multirow{2}{*}{260.6} & HOMO-2 $\rightarrow$ LUMO & 0.233 & 11 \\
& & HOMO $\rightarrow$ LUMO & 0.618 & 76 \\
\cline { 2 - 5 } & 258.5 & HOMO $\rightarrow$ LUMO & 0.665 & 89 \\
\hline
\end{tabular}

\begin{tabular}{|c|c|c|c|c|}
\hline \multirow{4}{*}[\mathrm{Zn}]{$_{2}+\mathrm{CO}_{2}$} & $\lambda(\mathrm{nm})$ & Assignment & Oscill.Str. & Wt. (\%) \\
\hline & 315.3 & $\begin{array}{c}\text { HOMO } \rightarrow \text { LUMO } \\
\text { HOMO } \rightarrow \text { LUMO+1 }\end{array}$ & $\begin{array}{l}-0.582 \\
0.375\end{array}$ & $\begin{array}{l}68 \\
28\end{array}$ \\
\hline & 314.6 & $\begin{array}{c}\text { HOMO } \rightarrow \text { LUMO } \\
\text { HOMO } \rightarrow \text { LUMO+1 }\end{array}$ & $\begin{array}{l}0.582 \\
-0.382\end{array}$ & $\begin{array}{l}68 \\
29\end{array}$ \\
\hline & 299.3 & $\begin{array}{l}\mathrm{HOMO} \rightarrow \text { LUMO }+1 \\
\mathrm{HOMO} \rightarrow \text { LUMO } 3\end{array}$ & $\begin{array}{l}-0.426 \\
-0.474\end{array}$ & $\begin{array}{l}36 \\
45\end{array}$ \\
\hline
\end{tabular}

\begin{tabular}{|c|c|c|c|c|}
\hline \multirow{6}{*}[\mathrm{Zn}]{$_{1}+\mathrm{CO}_{2}+\mathrm{ME}$} & $\lambda(\mathrm{nm})$ & Assignment & Oscill.Str. & Wt. (\%) \\
\hline & 257.8 & $\begin{array}{c}\mathrm{HOMO} \rightarrow \text { LUMO } \\
\mathrm{HOMO} \rightarrow \text { LUMO+3 }\end{array}$ & $\begin{array}{l}-0.337 \\
-0.582\end{array}$ & $\begin{array}{l}23 \\
68\end{array}$ \\
\hline & 253.0 & HOMO-3 $\rightarrow$ LUMO & 0.645 & 83 \\
\hline & & HOMO- $2 \rightarrow$ LUMO & 0.460 & 42 \\
\hline & 247.3 & $\mathrm{HOMO} \rightarrow$ LUMO & -0.393 & 31 \\
\hline & & $\mathrm{HOMO} \rightarrow \mathrm{LUMO}+3$ & 0.27356 & 15 \\
\hline
\end{tabular}

\begin{tabular}{|c|c|c|c|c|}
\hline \multirow{4}{*}[\mathbf{Zn}]{$_{2}+\mathrm{CO}_{2}+\mathrm{ME}$} & $\boldsymbol{\lambda}(\mathbf{n m})$ & Assignment & Oscill.Str. & Wt. (\%) \\
\cline { 2 - 5 } & 265.4 & $\mathrm{HOMO} \rightarrow$ LUMO & 0.683 & 93 \\
\cline { 2 - 5 } & 264.2 & $\mathrm{HOMO} \rightarrow$ LUMO & 0.695 & 97 \\
\cline { 2 - 5 } & 254.0 & $\mathrm{HOMO} \rightarrow$ LUMO+1 & 0.525 & 55 \\
& & HOMO $\rightarrow$ LUMO+3 & -0.428 & 37 \\
\hline
\end{tabular}

Chart 2. Excitation wavelengths $(\lambda)$ with their respective assignments, oscillation strengths and probability weights, calculated by TD-DFT for [Zn $]_{1}(\text { left) and [Zn }]_{2}$ (right) alone and with $\mathrm{ME}, \mathrm{CO}_{2}$ and both. 
In view of these findings, the only thing necessary to finish describing the ink degradation is the equilibrium ratio between monomers and dimers. Consequenlly, in order to get further information on the relative stability of the two species, the study of the formation of $[\mathrm{Zn}]_{2}$ from two isolated $[\mathrm{Zn}]_{1}$ units was envisaged.

\section{Dimerization}

As shown in our previous paper ${ }^{23}$, the tetramer is the most stable species in solid state whereas, in the ink, the dimer is found to be more abundant than the monomer. In this section, simulations will confirm the higher stability of $[\mathrm{Zn}]_{2}$.

Calculations based on Density Functional Theory (DFT) to elucidate the reaction path from two infinitely separated monomers were carried out at $0 \mathrm{~K}$. According to these simulations, when one monomer approaches each other, the total energy of the system is reduced by 18.7 $\mathrm{kcal} / \mathrm{mol}$, due to the formation of hydrogen bonds between their $[\mathrm{EA}]-[\mathrm{Ac}]$ pairs $\left([\mathrm{Zn}]_{1}-[\mathrm{Zn}]_{1}\right.$ state in Figure 8). As shown in Figure 8, the reaction goes through two acetate bridge formations. First, both hydrogen bonds are maintained while the $[A c]_{r i g h t}$ approaches to the $\mathrm{Zn}_{\text {left }}$ (state $\mathrm{A}$ in Figure 8). Then, the hydrogen bond between $[\mathrm{Ac}]_{\text {left }}$ and $[\mathrm{EA}]_{\text {right }}$ is cleaved and the first acetate bridge is formed (state $B$ ). Next, the $[E A]_{\text {left }}-[A c]_{\text {right }}$ hydrogen bond is cleaved and a new stable interaction is formed between both $[E A]$, while $[A c]_{\text {left }}$ starts approaching to $\mathrm{Zn}_{\text {right }}\left(\right.$ state $\mathrm{C}$ ). Finally, both acetate bridges are formed and the $[E A]_{\text {left }}-[A c]_{\text {right }}$ bond is maintained (state $\left.[\mathrm{Zn}]_{2}\right)$. From $2[\mathrm{Zn}]_{1}$ to $[\mathrm{Zn}]_{2}$ the total energy diminishes around $50 \mathrm{kcal} / \mathrm{mol}$.

This simulation indicates that dimers are highly preferred to monomers. Since, as seen in the previous section, the dimer has smaller gap energy, it is more sensitive to degradation by light.

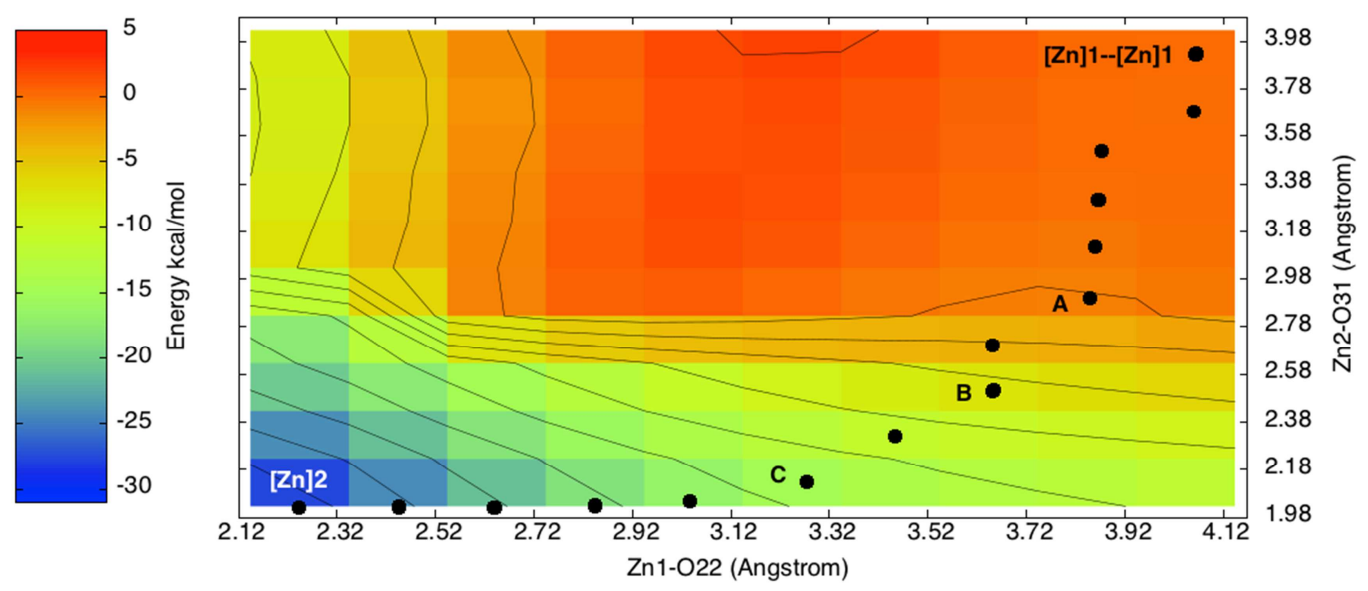


$[\mathrm{Zn}] 1-[\mathrm{Zn}] 1$

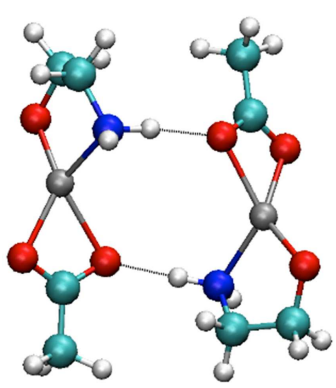

A

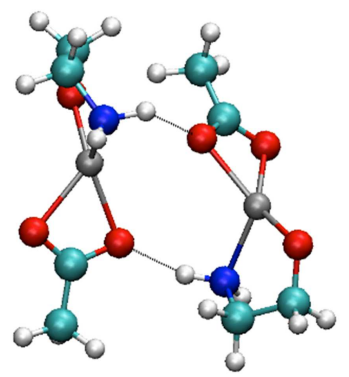

B

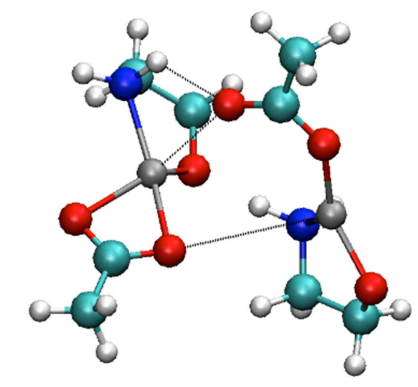

C

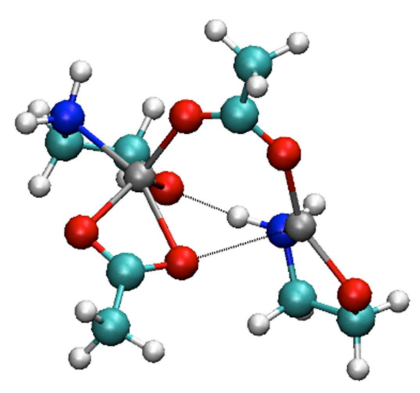

$[\mathrm{Zn}] 2$

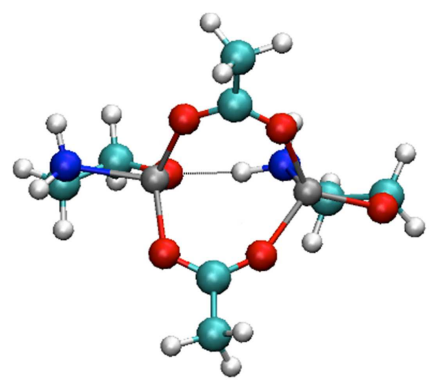

Figure 8. Potential energy surface with the most relevant structures during the dimerization process.

\section{CONCLUSIONS}

The present paper has reported on a detailed study, relying on experiments as well as on computational simulations, on the stability of an ink based on ZAD+EA for generating ZnO films. It has been shown that degradation is mainly driven by reaction of EA with atmospheric $\mathrm{CO}_{2}$, and that EA reactivity increases when it is dissolved in $\mathrm{ME}$ and, even further, in the $\mathrm{EA}+\mathrm{ME}+\mathrm{ZAD}$ ink. This has been explained by TD-DFT calculations as due to the fact that $\mathrm{N}$ and $O$ atoms of deprotonated EA become more nucleophilic in EA+ME and in EA+ME+ZAD, respectively. The diminution of EA concentration in the degraded ink has been seen by EGA and NMR experiments, which also delivered information about the degradation products.

Experiments have also shown that reactivity with $\mathrm{CO}_{2}$ is affected by illumination mainly when the sample contains $\mathrm{Zn}$. In fact, the energy required for the first electronic transition 
decreases when $\mathrm{EA}+\mathrm{ZAD}$ comes into contact with $\mathrm{ME}$ but $\mathrm{CO}_{2}$ destabilizes the precursor, acting as assistant during photodegradation. Finally, calculations make clear that the dimer is less stable under photoexcitation than the monomer. This is relevant because, in solution, the monomers tend to combine into dimers. The reaction path of this process has been elucidated.

In conclusion, for the first time, degradation of a sol-gel $\mathrm{ZnO}$ precursor ink containing EA has been described, and the factors influencing its stability have been detailed.

\section{ACKNOWLEDGEMENT}

Authors are grateful to Jordi Farjas for his help with EGA experiments, and to Angel Diéguez for his help with simulations. Also, we thank the Universitat de Barcelona for the Ajut per a Personal Investigador en Formació (APIF) grant given to Alberto Gómez-Núñez, and to the Ministerio de Educación, Cutura y Deporte for the Ayuda para la Formación de Personal Investigador (FPI) grant given to Santiago Alonso-Gil.

\section{SUPPORTING INFORMATION FOR PUBLICATION}

Contents :

Mathematical details for calculations

Table S1. Final atomic coordinates (in $\AA$ ) of the optimized EA.

Table S2. Final atomic coordinates (in $\AA$ ) of the optimized EA+ME

Table S3. Final atomic coordinates (in Å) of the optimized [Zn]1.

Table S4. Final atomic coordinates (in Å) of the optimized [Zn]1+ME.

Table S5. Final atomic coordinates (in $\AA$ ) of the optimized [Zn]1+CO2.

Table S6. Final atomic coordinates (in $\AA$ ) of the optimized [Zn]1+ME+CO2.

Table S7. Final atomic coordinates (in Å) of the optimized [Zn]2.

Table S8. Final atomic coordinates (in Å) of the optimized [Zn]2+ME. 
Table S9. Final atomic coordinates (in Å) of the optimized [Zn]2+CO2.

Table S10. Final atomic coordinates (in Å) of the optimized [Zn]2+ME+CO2.

Fig. S1. Partial view of the $1 \mathrm{H}-\mathrm{NMR}$ spectrum $(400 \mathrm{MHz})$ in the range $6.7<\delta<8.7 \mathrm{ppm}$ of the sample containing EA+ME after 8 weeks exposed to light and air.

\section{REFERENCES}

1 Özgür, Ü., Alivov, Ya.I., Liu, C., Teke, A., Reshchikov, M.A., Doğan, S., Avrutin, V., Cho, S.-J., Morkoç, H., A Comprehensive Review of ZnO Materials and Devices, J. Appl. Phys., 2005, 98, $0413011-103$.

2 Jule, L.T., Dejene, F.B., Roro, K.T., Urgessa, Z.N., Botha, J.R., Rapid Synthesis of Blue Emitting ZnO Nanoparticles for Fluorescent Applications, Physica B, 2016, 497, 71-77.

${ }^{3}$ Vallejos, S., Gràcia, I., Figueras, E., Pizurova, N., Hubálek, J., Cané, C., ZnO-Based Gas Microsensors Sensitive to $\mathrm{CO}$ at Room Temperature by Photoactivation, Procedia Engineering, 2016, 168, 415-418.

${ }^{4}$ Znaidi, L., Sol-Gel-Deposited ZnO Thin Films: A Review, Mater. Sci. Eng. B, 2010, 174, 18-30.

${ }^{5}$ Foo, K.L., Kashif, M., Hashim, U., Liu, W.-W., Effect of Different Solvents on the Structural and Optical Properties of Zinc Oxide Thin Films for Optoelectronic Applications, Ceram. Int., 2014, 40, 753-761.

6 Demes, T., Ternon, C., Riassetto, D., Roussel, H., Rapenne, L., Gélard, I., Jimenez, C., Stambouli, V., Langlet, M., New Insights in the Structural and Morphological Properties of SolGel Deposited ZnO Multilayer Films, J. Phys. Chem. Solids, 2016, 95, 43-55.

7 Joshi, B.N., Yoon, H., Kim, H.Y., Oh, J.H., Seong, Y.Y., James, S.C., Yoon, S.S., Effect of Zinc Acetate Concentration on Structural, Optical and Electrical Properties of $\mathrm{ZnO}$ Thin Films Deposited by Electrostatic Spray on an ITO Substrate, J. Electr. Soc., 2012, 159 H716-H721.

${ }^{8}$ Ayana, D.G., Ceccato, R., Collini, C., Lorenzelli, L., Prusakova, V., Dirè, S., Sol-Gel Derived Oriented Multilayer ZnO Thin Films with Memristive Response. Thin Solid Films, 2016, 615, 427-436. 
${ }^{9}$ Khodja, S., Touam, T., Chelouche, A., Boudjouan, F., Djouadi, D., Hadjoub, Z., Fischer, A., Boudrioua, A., Effects of Stabilizer Ratio on Structural, Morphological, Optical and Waveguide Properties of ZnO Nano-Structured Thin Films by a Sol-Gel Process, Superlattices Microstruct., 2014, 75, 485-495.

${ }^{10}$ Boudjouan, F., Chelouche, A., Touam, T., Djouadi, D., Khodja, S., Tazerout, M., Ouerdane, Y., Hadjoub, Z., Effects of Stabilizer Ratio on Photoluminescence Properties of Sol-Gel ZnO Nano-Structured Thin Films. J. Lumin., 2015, 158, 32-37.

${ }^{11}$ CheAni, N., Kamaruddin, S.A., Nayan, N., MohdTawil, S.N., Sahdan, M.Z., Effects of Ageing Time of ZnO Sol on Properties of ZnO Films by Sol Gel Spin Coating, Adv. Mat. Res., 2014, 925, 329-333.

12 Morvillo, P., Diana, R., Ricciardi, R., Bobeico, E., Minarini, C., High Efficiency Inverted Polymer Solar Cells with Solution-Processed ZnO Buffer Layer, J Sol-Gel Sci. Technol., 2015, 73, $550-556$.

${ }^{13}$ Singh, A., Kumar D., Khanna, P.K., Kumar M., Prasad, B., Post Annealing Effect on Structural and Optical Properties of ZnO Thin Films Derived by Sol-Gel Route, J. Mater. Sci. - Mater. Electron., 2013, 24, 4607-4613.

${ }^{14}$ Jeon, I., Ryan, J.W., Nakazaki, T., Yeo, K.S., Negishi, Y., Matsuo, Y., Air-Processed Inverted Organic Solar Cells Utilizing a 2-Aminoethanol-Stabilized ZnO Nanoparticle Electron Transport Layer that Requires No Thermal Annealing, J. Mater. Chem A, 2014, 2, 18754-18760.

${ }^{15}$ Caglar M., Ruzgar, S., Influence of the Deposition Temperature on the Physical Properties of High Electron Mobility ZnO Films by Sol-Gel Process, J. Alloys and Comp., 2015, 644, 101105.

${ }^{16}$ Aydemir, S., Karakaya, S., Effects of Withdrawal Speed on the Structural and Optical Properties of Sol-Gel Derived ZnO Thin Films, J. Magn. Magn. Matter., 2015, 373, 33-39.

${ }^{17}$ Gómez-Núñez, A., Alonso-Gil, S., López, C., Vilà, A., Electronic and dynamic DFT studies on the substituent effects of aminoalcohol stabilizers in sol-gel ZnO precursor, physica status solidi (a), 2016, 213, 2329-2335.

${ }^{18}$ Azizova, O.A., Islomov, A.I., Roshchupkin, D.I., Predvoditelev, D.A., Remizov, A.N., Free Radicals Formed during UV-Irradiation of Biological Membrane Lipids. Biofizika, 1979, 24, 396402. 
19 Mathis, C.L., Gist, B.M., Frederikson, C.K., Midkiff, K.M., Marvin, C.C., Visible Light Photooxidative Cyclization of Amino Alcohols to 1,3-Oxazines, Tetrahedron Lett., 2014, 54, 2101-2104.

${ }^{20}$ Sivakumar, K., Senthil Kumar, V., Muthukumarasamy, N., Thambidural, M., Senthil, T.S., Influence of $\mathrm{pH}$ on ZnO Nanocrystalline Thin Films Prepared by Sol-Gel Dip Coating Method, Bull. Mater. Sci., 2012, 35, 327-331.

${ }^{21}$ Zawadzka, A., Plóciennik, P., Strzelecki, J., Sahraoui, B., Transparent Amorphous Zinc Oxide Thin Films for NLO Applications, Opt. Mat., 2014, 37, 327-337.

${ }^{22}$ Vajargah, P.H., Abdizadeh, H., Ebrahimifard, R., Golobostanfard, M.R., Sol-Gel Derived ZnO Thin Films: Effect of Amino-Additives, Appl. Surf. Sci., 2013, 285P, 732-743.

${ }^{23}$ Gómez-Núñez, A., López, C., Alonso-Gil, S., Roura, P., Vilà, A., Study of a Sol-Gel Precursor and its Evolution Towards ZnO, Mat. Chem. Phys., 2015, 162, 645-651.

${ }^{24}$ Gómez-Núñez, A., Alonso-Gil, S., López, C., Roura, P., Vilà, A., Molecular Dynamics Study of ZnO Formation from a Sol-Gel Ink Containing Ethanolamine, Manuscript in preparation.

${ }^{25}$ Frisch, M.J.; Trucks, G.W.; Schlegel, H.B.; Scuseria, G.E.; Robb, M.A.; Cheeseman, J.R.; Montgomery, J.A. Jr.; Vreven, T.; Kudin, K.N.; Burant, J.C.; et al., "Gaussian 03, Revision C.02", Gaussian, Inc., 2004, Wallingford CT.

${ }^{26}$ Becke, A.D., Density-Functional Thermochemistry. III. The Role of Exact Exchange, J. Chem. Phys., 1993, 98, 5648-5652.

${ }^{27}$ Lee, C., Yang, W., Parr, R.G., Development of the Colle-Salvetti Correlation-Energy Formula into a Functional of the Electron Density, Phys. Rev. B, 1988, 37, 785-789.

${ }^{28}$ Wadt, W.R., Hay, P.J., Ab Initio Effective Core Potentials for Molecular Calculations. Potentials for Main Group Elements Na to Bi, J. Chem. Phys., 1985, 82, 284.

${ }^{29}$ Hay P.J., Wadt, W.R., Ab Initio Effective Core Potentials for Molecular Calculations. Potentials for K to Au Including the Outermost Core Orbitals, J. Chem. Phys., 1985, 82, 299.

30 Tomasi, J., Mennucci, B., Cammi, R., Quantum Mechanical Continuum Solvation Models, Chem. Rev., 2005, 105, 2999-3094. 
${ }^{31}$ Furche, F., Ahlrichs, R., Adiabatic Time-Dependent Density Functional Methods for Excited State Properties, J. Chem. Phys., 2002, 117, 7433-7447. Erratum: J. Chem. Phys., 2004, 121, 12772-12773.

${ }^{32}$ Scalmani, G., Frisch, M.J., Mennucci, B., Tomasi, J., Cammi, R., Barone, V., Geometries and Properties of Excited States in the Gas Phase and in Solution: Theory and Application of a TimeDependent Density Functional Theory Polarizable Continuum Model, J. Chem. Phys., 2006, 124, 94107-94122.

${ }^{33}$ Kortunov, P.V., Siskin, M., Saunders-Baugh, L., Calabro, D.C., In Situ Nuclear Magnetic Resonance Mechanistic Studies of Carbon Dioxide Reactions with Liquid Amines in Nonaqueous Systems: Evidence for the Formation of Carbamic Acids and Zwitterionic Species, Energy Fuels, 2015, 29, 5940-5966.

${ }^{34}$ Quaranta, E., Aresta, M., The Chemistry of $\mathrm{N}-\mathrm{CO}_{2}$ Bonds: Synthesis of Carbamic Acids and Their Derivatives, Isocyanates, and Ureas, in Carbon Dioxide as Chemical Feedstock (ed M. Aresta), 2010, Wiley-VCH Verlag GmbH \& Co. KGaA, Weinheim, Germany.

35 Vevelstad, S.J., Johansen, M.T., Knuutila, H., Svendsen, H.F., Extensive Dataset for Oxidative Degradation of Ethanolamine at $55-75^{\circ} \mathrm{C}$ and Oxygen Concentrations from 6 to $98 \%$. International Journal of Greenhouse Gas Control, 2016, 50, 158-178.

${ }^{36}$ Taylor, P.J., The "Basicity Method" for Estimating Tautomer Ratio: A Radical Re-Appraisal, in Tautomerism: Methods and Theories (ed L. Antonov), 2013, Wiley-VCH Verlag GmbH \& Co. KGaA, Weinheim, Germany.

37 Lázár, L., Fülöp, F., Recent Developments in the Ring-Chain Tautomerism of 1,3Heterocycles. Eur. J. Org. Chem., 2003, 16, 3025-3042.

${ }^{38}$ Gómez-Núñez A, Roura, P., López, C., Vilà, A., Comparison of the thermal decomposition processes of severalaminoalcohol-based $\mathrm{ZnO}$ inks with one containing ethanolamine. Appl. Surf. Sci., 2016, 381, 48-53.

39 Ge, X., Shaw, S.L., Zhang, Q., Toward Understanding Amines and Their Degradation Products from Postcombustion $\mathrm{CO}_{2}$ Capture Processes with Aerosol Mass Spectrometry, Environ. Sci. Technol., 2014, 48, 5066-5075. 
TABLE OF CONTENTS GRAPHIC
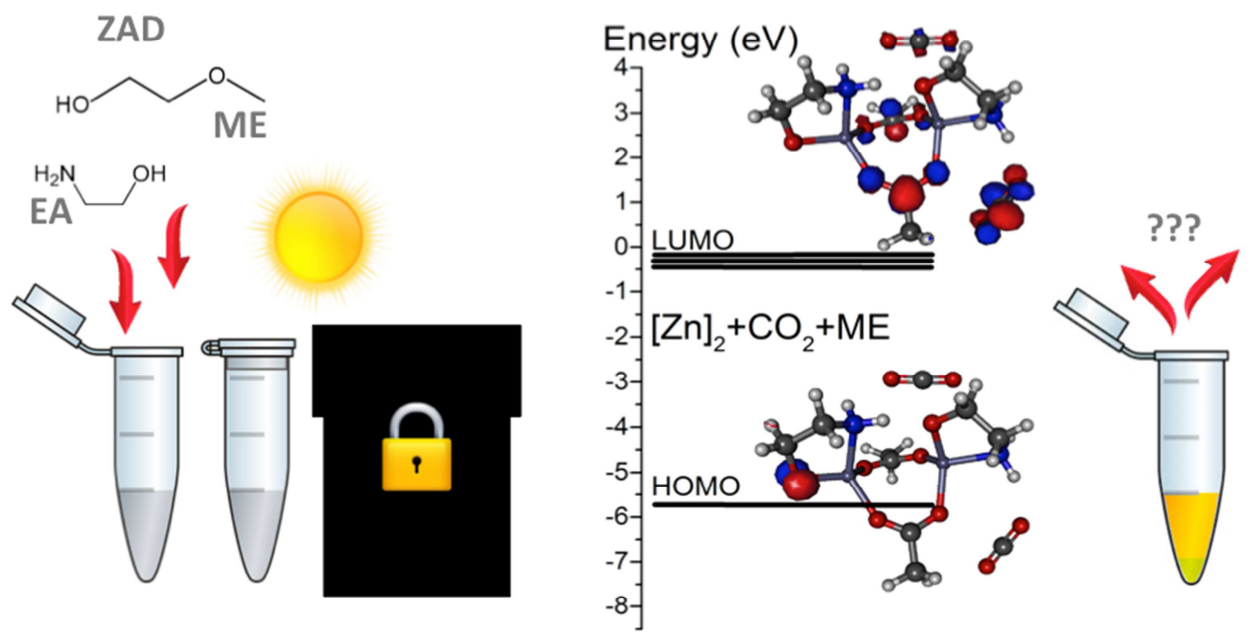
Supporting Information for Publication

\title{
Role of ethanolamine on the stability of a sol-gel ZnO ink
}

\author{
A. Gómez-Núñez ${ }^{1}$, S. Alonso-Gil' ${ }^{2}$, C. López ${ }^{2}$, P. Roura ${ }^{3}$ and A. Vilà ${ }^{1 *}$ \\ ${ }^{1}$ Department of Engineering: Electronics, University of Barcelona, Martí i Franquès 1, E-08028- \\ Barcelona, Spain. Institute of Nanoscience and Nanotechnology (IN2UB), University of \\ Barcelona, Joan XXIII s/n, E-08028-Barcelona, Spain. avila@el.ub.edu \\ ${ }^{2}$ Department of Inorganic and Organic Chemistry, University of Barcelona, Martí i Franquès 1, \\ E-08028-Barcelona, Spain. \\ ${ }^{3}$ Department of Physics, University of Girona, Campus Montilivi, Edif. PII, E-17003-Girona, \\ Spain.
}

Contents :

Mathematical details for calculations

Table S1. Final atomic coordinates (in $\AA$ ) of the optimized EA.

Table S2. Final atomic coordinates (in $\AA$ ) of the optimized EA+ME

Table S3. Final atomic coordinates (in $\AA$ ) of the optimized $[\mathrm{Zn}]_{1}$.

Table S4. Final atomic coordinates (in $\AA$ ) of the optimized $[Z n]_{1}+M E$.

Table S5. Final atomic coordinates (in $\AA$ ) of the optimized $[\mathrm{Zn}]_{1}+\mathrm{CO}_{2}$.

Table S6. Final atomic coordinates (in $\AA$ ) of the optimized $[\mathrm{Zn}]_{1}+\mathrm{ME}+\mathrm{CO}_{2}$.

Table S7. Final atomic coordinates (in $\AA$ ) of the optimized $[\mathrm{Zn}]_{2}$.

Table S8. Final atomic coordinates (in $\AA$ ) of the optimized $[\mathrm{Zn}]_{2}+\mathrm{ME}$.

Table S9. Final atomic coordinates (in $\AA$ ) of the optimized $[\mathrm{Zn}]_{2}+\mathrm{CO}_{2}$. 
Table S10. Final atomic coordinates (in $\AA$ ) of the optimized $[\mathrm{Zn}]_{2}+\mathrm{ME}+\mathrm{CO}_{2}$.

Fig. S1. Partial view of the ${ }^{1} \mathrm{H}-\mathrm{NMR}$ spectrum $(400 \mathrm{MHz})$ in the range $6.7<\delta<8.7 \mathrm{ppm}$ of the sample containing EA+ME after 8 weeks exposed to light and air.

Complete reference ${ }^{25}$. 


\section{MATHEMATICAL DETAILS FOR CALCULATIONS}

Time-Dependent Density Functional Theory (TD-DFT) method $^{40}$ is based on the excitation energy calculations from the eigenvalues of the matrix $\mathbf{H}^{(2)} \mathbf{H}^{(1)}$, where $\mathbf{H}^{(1)}$ and $\mathbf{H}^{(2)}$ are the Hessian's real and imaginary orbitals respectively,

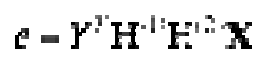

Kohn and Sham ${ }^{41}$ (KS) developed a method to approximate the expression of the Energy functional. This method is a fictitious system $\mathrm{S}$ of non-interacting electrons, chosen to have the same density as the physical system. The total Hamiltonian (HKS) is then the sum of all

monoelectronic hamiltonians, $\hat{H}_{\mathrm{s}}$, applied to every spin-orbital, $\psi^{\prime}$, generating the ground state wavefunction, $\varphi_{1}^{\prime}$. The results are the expressions known as the KS equations:

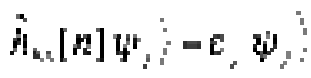

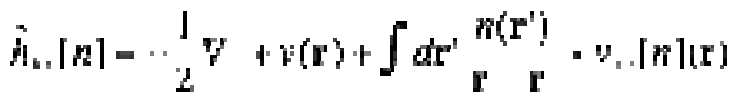

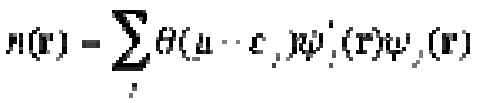

$$
\begin{aligned}
& \int d r n(r)-n
\end{aligned}
$$

The main objective of the DFT method is then to find the suitable energy that minimizes the expression of EKS. From the form of the Schrödinger equation one can see that the energy functional contains three terms: the kinetic energy $(T)$, interaction with the external potential $\left(V_{e x}\right)$, the Hartree potential $\left(V_{h}\right)$ and the electron-electron interaction $\left(V_{e e}\right)$, and thus one may write the functional as $E=T+V_{e x}+V_{h}+E_{x c}$.

This set of non-linear equations (the KS equations) describes the behavior of non-interacting "electrons" in an effective local potential. For the exact functional, and thus exact local potential, the "orbitals" yield the exact ground state density and exact ground state energy. The KS approach achieves an exact correspondence of the density and ground state energy of a system consisting of non-interacting fermions and the "real" many body system described by the Schrödinger equation.

For calculations in which the energy surface is the quantity of primary interest, DFT offers a practical and potential highly accurate alternative to the wavefunction methods. In practice, the utility of the theory rests on the approximation used for the exchange-correlation functional, $E_{x c}$. 
Thus, using the same nomenclature as in reference ${ }^{40}$, the virtual orbitals are labelled as $a, b$, c; where $\mathrm{i}, \mathrm{j}$ and $\mathrm{k}$ are the occupied orbitals and $\mathrm{p}$ and $\mathrm{q}$ are any molecular orbitals (virtually occupied). The excitation energy derivative $\Delta \mathrm{E}$ is thus:

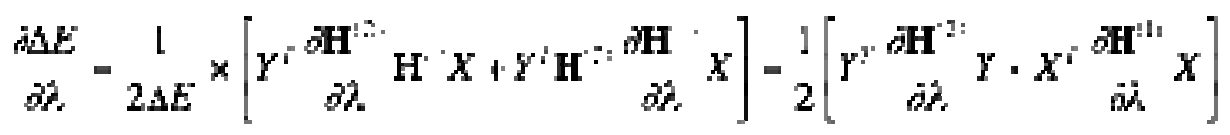

The calculation of the electronic energy derivative leads to the optimal algorithm as follows:

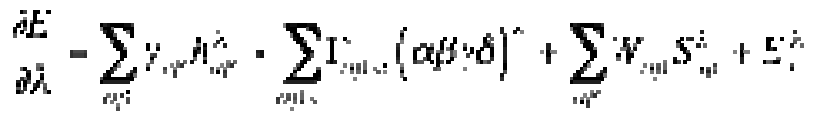

Where $h_{\alpha \beta}^{\lambda}$ and $(\alpha \beta \mid \gamma \delta)^{\lambda}$ are the derivatives of the one- and two-electron integrals in the atomic orbital $(\mathrm{AO})$ basis, respectively, and $\mathrm{S}$ is the derivative of the overlap integrals. The coefficients $\gamma$ and $\Gamma$ are the relaxed one- and two-particle density matrices, respectively, and $E_{\mathrm{xc}}$ contains the exchange-correlation functional terms.

The operator $d / d \lambda$ is presented as:

$$
\frac{d}{d \lambda}-\rho^{2}=\frac{\partial}{\partial \rho} \cdot \frac{\varepsilon}{\partial g}
$$

And every component of the algorithm:

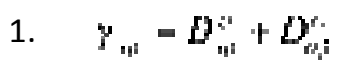

being the ground-state one-particle density matrix

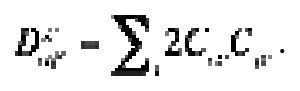

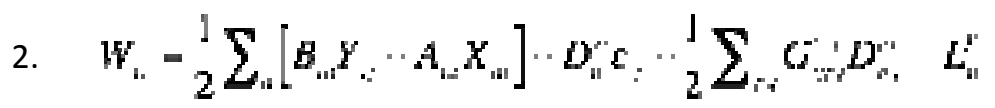

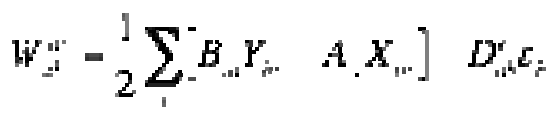

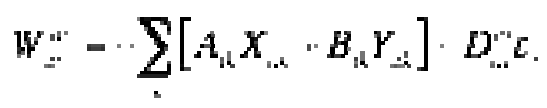

$$
W_{m i}-22 c c_{m} c_{n}
$$


3.

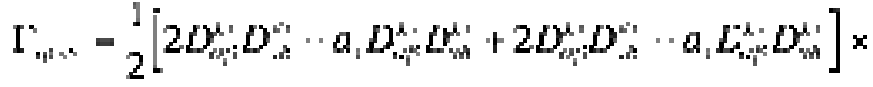

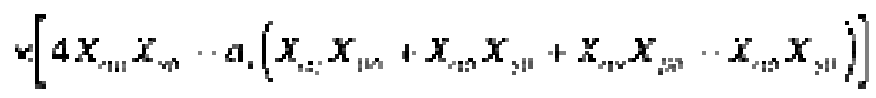

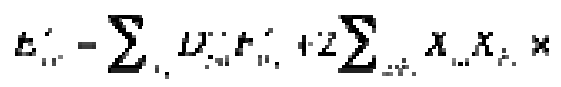

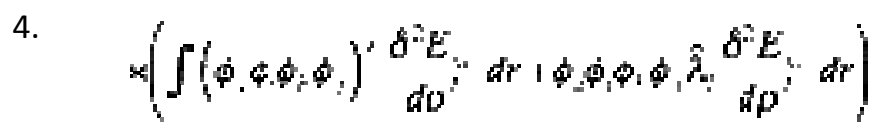

\section{REFERENCES}

${ }^{40}$ Van Caillie, C., Amos, R.D., Geometric derivatives of density functional theory excitation energies using gradient-corrected functionals, Chem. Phys. Lett., 2000, 317, 159-164.

${ }^{41}$ Kohn, W., Sham, L.J., Self-consistent equations including exchange and correlation effects, Physical Review, 1965, 140, A1133-A1138. 


$\begin{array}{llll}\text { O } & 0.0305170000 & 0.0748430000 & 0.0216300000 \\ \text { N } & 0.0349490000 & -0.0416000000 & 2.8116230000 \\ \text { C } & 1.3323420000 & -0.0048700000 & 2.0991570000 \\ \text { H } & 2.1440200000 & -0.5401660000 & 2.6222040000 \\ \text { C } & 1.1379840000 & -0.5907340000 & 0.6859760000 \\ \text { H } & 2.0290510000 & -0.4279560000 & 0.0705240000 \\ \text { H } & 0.9527120000 & -1.6772700000 & 0.7521770000 \\ \text { H } & 1.6294880000 & 1.0469700000 & 2.0075440000 \\ \text { H } & -0.2414220000 & -0.9591520000 & 3.1535880000 \\ \text { H } & -0.1028580000 & 0.6865030000 & 3.5058450000 \\ \text { H } & -0.6444520000 & 0.2344940000 & 0.7252210000\end{array}$

Table S1. Final atomic coordinates (in $\AA$ ) of the optimized EA.

\begin{tabular}{|c|c|c|c|}
\hline $\mathrm{O}$ & 1.3566950000 & -0.7090970000 & -0.1552430000 \\
\hline $\mathrm{N}$ & -1.3376760000 & -0.5558150000 & 0.1213550000 \\
\hline C & -0.6386140000 & 0.7029860000 & -0.2416010000 \\
\hline $\mathrm{H}$ & -1.1056860000 & 1.6079240000 & 0.1770870000 \\
\hline C & 0.8255400000 & 0.5960990000 & 0.2364550000 \\
\hline $\mathrm{H}$ & 1.4488240000 & 1.3669070000 & -0.2279430000 \\
\hline $\mathrm{H}$ & 0.8769420000 & 0.7099100000 & 1.3309520000 \\
\hline $\mathrm{H}$ & -0.6582390000 & 0.7896700000 & -1.3342910000 \\
\hline $\mathrm{H}$ & -1.6352460000 & -0.5959930000 & 1.0953640000 \\
\hline $\mathrm{H}$ & -2.1004880000 & -0.8033830000 & -0.5045630000 \\
\hline $\mathrm{H}$ & 0.5625090000 & -1.3060620000 & -0.1132790000 \\
\hline
\end{tabular}


Table S2. Final atomic coordinates (in $\AA$ ) of the optimized EA+ME.

\begin{tabular}{|c|c|c|c|}
\hline C & 5.510948560810 & 4.230430816229 & 5.112007398233 \\
\hline C & 4.896293723616 & 5.641963678690 & 5.151391109096 \\
\hline C & 7.756197454255 & 5.732695548846 & 9.433710573137 \\
\hline C & 8.536616791289 & 5.774222432280 & 10.724128228751 \\
\hline $\mathrm{H}$ & 4.834111427559 & 3.514328376887 & 4.611525770599 \\
\hline $\mathrm{H}$ & 4.766333486044 & 5.979912253554 & 4.102057690633 \\
\hline $\mathrm{H}$ & 3.868923213076 & 5.561986171347 & 5.585895507211 \\
\hline $\mathrm{H}$ & 6.462350899533 & 4.265922557223 & 4.556429961127 \\
\hline $\mathrm{H}$ & 8.754673104150 & 6.827617325212 & 10.965492590293 \\
\hline $\mathrm{H}$ & 9.495199563006 & 5.249936928928 & 10.613328954057 \\
\hline $\mathrm{H}$ & 7.949582123988 & 5.349260503299 & 11.548773858021 \\
\hline H & 4.990329109360 & 3.476134862775 & 6.990428939910 \\
\hline $\mathrm{H}$ & 6.509566628423 & 3.036400131345 & 6.523513230069 \\
\hline $\mathrm{O}$ & 6.474494843641 & 5.729174644932 & 9.460804830659 \\
\hline $\mathrm{O}$ & 8.377217951871 & 5.724121694991 & 8.311722035561 \\
\hline $\mathrm{O}$ & 5.690514423958 & 6.566593305444 & 5.853832901811 \\
\hline $\mathrm{Zr}$ & 6.502643634282 & 5.726063017071 & 7.351478852678 \\
\hline $\mathrm{N}$ & 5.834944173996 & 3.808230870638 & 6.507485633611 \\
\hline
\end{tabular}

Table S3. Final atomic coordinates (in $\AA$ ) of the optimized $[Z n]_{1}$.
C $\quad 2.8459670000$
0.7122610000
$-0.3867440000$
C
2.8527580000
$-0.5956340000$
0.4485470000 


\begin{tabular}{|c|c|c|c|}
\hline C & -2.4144260000 & 0.0674070000 & 0.0427130000 \\
\hline C & -3.9275110000 & 0.1047110000 & 0.0096250000 \\
\hline $\mathrm{H}$ & 3.6955550000 & 1.3543770000 & -0.1169360000 \\
\hline $\mathrm{H}$ & 3.7396330000 & -1.1766820000 & 0.1465280000 \\
\hline $\mathrm{H}$ & 2.9783790000 & -0.3337290000 & 1.5168410000 \\
\hline $\mathrm{H}$ & 2.9195400000 & 0.4643920000 & -1.4518290000 \\
\hline $\mathrm{H}$ & -4.3178460000 & -0.8375860000 & 0.4162160000 \\
\hline $\mathrm{H}$ & -4.2844310000 & 0.1928550000 & -1.0209460000 \\
\hline $\mathrm{H}$ & -4.3112290000 & 0.9300290000 & 0.6131170000 \\
\hline $\mathrm{H}$ & 1.5204460000 & 1.9643160000 & 0.6831900000 \\
\hline $\mathrm{H}$ & 1.3428030000 & 2.0835120000 & -0.9617510000 \\
\hline $\mathrm{O}$ & -1.7097940000 & 0.6760910000 & 0.9737480000 \\
\hline 0 & -1.7479520000 & -0.6251770000 & -0.8709350000 \\
\hline $\mathrm{O}$ & 1.6510330000 & -1.3729960000 & 0.2421180000 \\
\hline $\mathrm{Zn}$ & 0.1429480000 & -0.1948940000 & -0.0635850000 \\
\hline $\mathrm{N}$ & 1.5345280000 & 1.4356470000 & -0.1944550000 \\
\hline
\end{tabular}

Table S4. Final atomic coordinates (in Å) of the optimized $[\mathrm{Zn}]_{1}+\mathrm{ME}$.

$\begin{array}{cccc}\text { Zn } & -0.6263380000 & -0.7430500000 & -0.1488900000 \\ \text { O } & 1.4715790000 & -0.1950690000 & -0.2946010000 \\ \text { O } & 0.7651470000 & -2.2011190000 & 0.3822800000 \\ \text { O } & -2.1875810000 & -0.5699220000 & -1.2054890000 \\ \text { N } & -1.4989340000 & 0.6529070000 & 1.2450270000 \\ & & & \\ \text { C } & -2.9497410000 & 0.6340400000 & 0.8208440000 \\ \text { H } & -3.4792900000 & 1.5346230000 & 1.1641940000\end{array}$




\begin{tabular}{|c|c|c|c|}
\hline C & -3.0408280000 & 0.4824760000 & -0.7252120000 \\
\hline $\mathrm{H}$ & -4.0896890000 & 0.2610800000 & -0.9781350000 \\
\hline $\mathrm{H}$ & -2.7835830000 & 1.4506080000 & -1.1973690000 \\
\hline $\mathrm{H}$ & -3.4055470000 & -0.2448760000 & 1.2926160000 \\
\hline C & 1.7688180000 & -1.4004030000 & 0.1124160000 \\
\hline C & 3.1910760000 & -1.8715440000 & 0.2491140000 \\
\hline $\mathrm{H}$ & 3.4202150000 & -2.5560180000 & -0.5776850000 \\
\hline $\mathrm{H}$ & 3.3124730000 & -2.4317640000 & 1.1815390000 \\
\hline $\mathrm{H}$ & 3.8827660000 & -1.0274330000 & 0.2129280000 \\
\hline $\mathrm{H}$ & -1.0374360000 & 1.5444150000 & 1.0347850000 \\
\hline $\mathrm{H}$ & -1.3871380000 & 0.4468190000 & 2.2391890000 \\
\hline C & 1.8477490000 & 2.4933460000 & -0.1154580000 \\
\hline 0 & 0.7290340000 & 2.5460500000 & 0.3035370000 \\
\hline 0 & 2.9652550000 & 2.5095870000 & -0.5195750000 \\
\hline
\end{tabular}

Table S5. Final atomic coordinates (in $\AA$ ) of the optimized $[\mathrm{Zn}]_{1}+\mathrm{CO}_{2}$.

\begin{tabular}{cccc} 
Zn & -0.7050290000 & -0.7483270000 & -0.0887900000 \\
O & 1.4929450000 & -0.2616560000 & -0.3404770000 \\
O & 0.7258400000 & -2.2269560000 & 0.4084070000 \\
O & -2.3700400000 & -0.6800390000 & -1.0786760000 \\
N & -1.4619840000 & 0.8628730000 & 1.1206180000 \\
C & -2.9304850000 & 0.8578010000 & 0.7860700000 \\
H & -3.3979600000 & 1.8245150000 & 1.0189970000 \\
C & -3.1255310000 & 0.4956520000 & -0.7093180000 \\
\hline H & -4.2019730000 & 0.3245750000 & -0.8733450000
\end{tabular}




\begin{tabular}{|c|c|c|c|}
\hline $\mathrm{H}$ & -2.8315660000 & 1.3657390000 & -1.3273700000 \\
\hline $\mathrm{H}$ & -3.3970680000 & 0.0858600000 & 1.4090350000 \\
\hline C & 1.7470820000 & -1.4614220000 & 0.0932950000 \\
\hline C & 3.1545510000 & -1.9865220000 & 0.2239500000 \\
\hline $\mathrm{H}$ & 3.3218430000 & -2.7646870000 & -0.5313540000 \\
\hline $\mathrm{H}$ & 3.2929480000 & -2.4484720000 & 1.2071560000 \\
\hline $\mathrm{H}$ & 3.8841520000 & -1.1871020000 & 0.0805290000 \\
\hline $\mathrm{H}$ & -0.9902750000 & 1.7168680000 & 0.8082910000 \\
\hline $\mathrm{H}$ & -1.3011170000 & 0.7504760000 & 2.1232690000 \\
\hline C & 2.0498360000 & 2.4655010000 & -0.1556960000 \\
\hline $\mathrm{O}$ & 0.9011380000 & 2.6237570000 & 0.1232440000 \\
\hline $\mathrm{O}$ & 3.2042480000 & 2.3593770000 & -0.4282050000 \\
\hline
\end{tabular}

Table S6. Final atomic coordinates (in $\AA$ ) of the optimized $[\mathrm{Zn}]_{1}+\mathrm{ME}+\mathrm{CO}_{2}$.

\begin{tabular}{|c|c|c|c|}
\hline 0 & 0.9903640000 & 0.9592310000 & -1.8502540000 \\
\hline $\mathrm{H}$ & 3.2811270000 & 0.6507700000 & 1.1452350000 \\
\hline $\mathrm{H}$ & 0.4697590000 & 2.5322090000 & -3.9540360000 \\
\hline $\mathrm{H}$ & 5.1519720000 & -0.6664660000 & 0.2963230000 \\
\hline 0 & 3.6266800000 & -1.0109900000 & -1.0947920000 \\
\hline C & 4.1534900000 & -1.1317640000 & 0.2365330000 \\
\hline C & 0.0539600000 & 1.8325740000 & -1.9683280000 \\
\hline $\mathrm{H}$ & 1.0868890000 & 3.5735470000 & -2.6703500000 \\
\hline C & 3.2389430000 & -0.4362760000 & 1.2900260000 \\
\hline $\mathrm{C}$ & 0.2329530000 & 2.9547080000 & -2.9713860000 \\
\hline $\mathrm{Zn}$ & 1.7332630000 & -0.7495790000 & -1.0770980000 \\
\hline
\end{tabular}




\begin{tabular}{|c|c|c|c|}
\hline $\mathrm{H}$ & 3.5755160000 & -0.6628930000 & 2.3140050000 \\
\hline $\mathrm{H}$ & 1.0921540000 & -0.2733560000 & 1.5530820000 \\
\hline $\mathrm{N}$ & 1.8116030000 & -0.8530360000 & 1.0669080000 \\
\hline $\mathrm{H}$ & 4.2712710000 & -2.1976850000 & 0.5227210000 \\
\hline $\mathrm{H}$ & -0.6671370000 & 3.5693780000 & -3.0292420000 \\
\hline 0 & -1.0386360000 & 1.8040970000 & -1.2590070000 \\
\hline $\mathrm{H}$ & 1.6752770000 & -1.8307320000 & 1.3416570000 \\
\hline $\mathrm{H}$ & -1.7689360000 & -0.2147820000 & 3.3693580000 \\
\hline 0 & -0.5071480000 & 0.4283010000 & 1.8121640000 \\
\hline $\mathrm{Zn}$ & -1.4520590000 & 0.4192310000 & 0.112026000 \\
\hline $\mathrm{C}$ & -1.3745340000 & 0.7165920000 & 2.9165390000 \\
\hline 0 & -1.7803820000 & -1.2966600000 & -0.8355840000 \\
\hline $\mathrm{H}$ & -3.7581870000 & 0.1871020000 & 1.4385160000 \\
\hline $\mathrm{H}$ & -0.8349100000 & 1.2618060000 & 3.7078630000 \\
\hline $\mathrm{H}$ & -2.4416100000 & -3.7594850000 & -1.4777680000 \\
\hline C & -1.0313650000 & -2.1320970000 & -1.4974470000 \\
\hline 0 & 0.2431850000 & -2.0105540000 & -1.6217130000 \\
\hline $\mathrm{N}$ & -3.1964550000 & 1.0157060000 & 1.2225050000 \\
\hline C & -2.5675580000 & 1.6029550000 & 2.4670000000 \\
\hline $\mathrm{C}$ & -1.7225040000 & -3.3055540000 & -2.1671650000 \\
\hline $\mathrm{H}$ & -2.2826050000 & -2.9412580000 & -3.0378490000 \\
\hline $\mathrm{H}$ & -3.3053660000 & 1.7164090000 & 3.2748070000 \\
\hline $\mathrm{H}$ & -3.7801060000 & 1.6953750000 & 0.7306060000 \\
\hline $\mathrm{H}$ & -2.1918090000 & 2.5950430000 & 2.1908700000 \\
\hline $\mathrm{H}$ & -0.9870990000 & -4.0418760000 & -2.4967440000 \\
\hline
\end{tabular}

Table S7. Final atomic coordinates (in $\AA$ ) of the optimized $[Z n]_{2}$. 


\begin{tabular}{|c|c|c|c|}
\hline 0 & -1.0857360000 & -0.9868340000 & 1.6895540000 \\
\hline $\mathrm{H}$ & -2.0319400000 & 2.7877350000 & 0.9406340000 \\
\hline $\mathrm{H}$ & -0.6882430000 & -2.9572370000 & 3.4570000000 \\
\hline $\mathrm{H}$ & -4.4177590000 & 2.4978200000 & 0.5077370000 \\
\hline 0 & -3.6235350000 & 0.5562630000 & 0.3602180000 \\
\hline $\mathrm{C}$ & -3.7222340000 & 1.9156470000 & -0.1214210000 \\
\hline C & 0.0356550000 & -1.3580730000 & 2.2165410000 \\
\hline $\mathrm{H}$ & -0.4099840000 & -1.4379390000 & 4.3142190000 \\
\hline $\mathrm{C}$ & -2.3441110000 & 2.6355200000 & -0.1009050000 \\
\hline $\mathrm{C}$ & -0.0092010000 & -2.1013610000 & 3.5383610000 \\
\hline $\mathrm{Zn}$ & -1.8424390000 & -0.1637560000 & -0.0057500000 \\
\hline $\mathrm{H}$ & -2.4125600000 & 3.6207660000 & -0.5863900000 \\
\hline $\mathrm{H}$ & -0.3170850000 & 2.0055690000 & -0.4839470000 \\
\hline $\mathrm{N}$ & -1.3042510000 & 1.7674560000 & -0.7493100000 \\
\hline $\mathrm{H}$ & -4.1174080000 & 1.9426840000 & -1.1570930000 \\
\hline $\mathrm{H}$ & 0.9871490000 & -2.4404070000 & 3.8282410000 \\
\hline $\mathrm{O}$ & 1.1949270000 & -1.1201440000 & 1.6786660000 \\
\hline $\mathrm{H}$ & -1.3945470000 & 1.7827060000 & -1.7690500000 \\
\hline $\mathrm{H}$ & 2.6256290000 & 2.7371770000 & -1.3798310000 \\
\hline 0 & 1.3235400000 & 1.8350700000 & 0.0137150000 \\
\hline $\mathrm{Zn}$ & 1.6351340000 & -0.1086690000 & -0.0137710000 \\
\hline $\mathrm{C}$ & 2.5305400000 & 2.5660600000 & -0.2907200000 \\
\hline 0 & 1.0536560000 & -1.3356830000 & -1.4990070000 \\
\hline $\mathrm{H}$ & 3.9722990000 & 0.2884090000 & -1.2466690000 \\
\hline $\mathrm{H}$ & 2.5213530000 & 3.5525630000 & 0.1996420000 \\
\hline & & $\mathrm{S} 12$ & \\
\hline
\end{tabular}




\begin{tabular}{llll} 
H & 0.6632880000 & -2.5140940000 & -3.8211660000 \\
C & -0.0737100000 & -1.8232230000 & -1.9201840000 \\
O & -1.2258170000 & -1.4922300000 & -1.4354780000 \\
N & 3.7172500000 & 0.3674700000 & -0.2575980000 \\
C & 3.7796430000 & 1.8007380000 & 0.2104090000 \\
C & -0.0188060000 & -2.8522970000 & -3.0342650000 \\
H & 0.3767350000 & -3.7950810000 & -2.6355600000 \\
H & 4.7034140000 & 2.2910720000 & -0.1264600000 \\
H & 4.3442180000 & -0.2311270000 & 0.2845680000 \\
\hline H & 3.7748230000 & 1.7780550000 & 1.3062110000 \\
H & -1.0141700000 & -3.0300100000 & -3.4463110000
\end{tabular}

Table S8. Final atomic coordinates (in Å) of the optimized $[\mathrm{Zn}]_{2}+\mathrm{ME}$.

\begin{tabular}{|c|c|c|c|}
\hline $\mathrm{O}$ & 0.0000000000 & 0.0000000000 & 0.0000000000 \\
\hline $\mathrm{H}$ & 3.7860640000 & 0.0000000000 & 0.0000000000 \\
\hline $\mathrm{H}$ & -1.4675420000 & 2.0783000000 & 0.0000000000 \\
\hline $\mathrm{H}$ & 4.4031910000 & 0.3365100000 & -2.3337190000 \\
\hline 0 & 2.3827510000 & -0.2026140000 & -2.4186600000 \\
\hline C & 3.7510050000 & -0.5255790000 & -2.1149920000 \\
\hline $\mathrm{C}$ & -0.8445160000 & 0.2446810000 & 0.9307470000 \\
\hline $\mathrm{H}$ & -1.0303810000 & 2.2256980000 & 1.7172110000 \\
\hline $\mathrm{C}$ & 3.9400510000 & -0.8973120000 & -0.6129520000 \\
\hline $\mathrm{C}$ & -1.5347440000 & 1.5919990000 & 0.9753280000 \\
\hline $\mathrm{Zn}$ & 1.1930120000 & -1.0918030000 & -1.2179170000 \\
\hline $\mathrm{H}$ & 4.9578180000 & -1.2744170000 & -0.4264650000 \\
\hline $\mathrm{H}$ & 2.7427940000 & -1.9849220000 & 0.8244890000 \\
\hline
\end{tabular}




\begin{tabular}{|c|c|c|c|}
\hline $\mathrm{N}$ & 2.8934980000 & -1.8953680000 & -0.2021320000 \\
\hline $\mathrm{H}$ & 4.1069920000 & -1.3729370000 & -2.7362320000 \\
\hline $\mathrm{H}$ & -2.5768250000 & 1.4811790000 & 1.2853680000 \\
\hline $\mathrm{O}$ & -1.1163730000 & -0.6260930000 & 1.8743550000 \\
\hline $\mathrm{H}$ & 3.1005840000 & -2.8278160000 & -0.5713790000 \\
\hline $\mathrm{H}$ & 2.4940040000 & -3.7238850000 & 3.8303300000 \\
\hline 0 & 1.8207600000 & -2.4566290000 & 2.2979230000 \\
\hline $\mathrm{Zn}$ & -0.1004830000 & -2.3703580000 & 1.9307010000 \\
\hline C & 2.1123900000 & -2.6971970000 & 3.6872240000 \\
\hline $\mathrm{O}$ & -0.7297310000 & -3.5276900000 & 0.4411250000 \\
\hline $\mathrm{H}$ & -0.2505540000 & -4.1688740000 & 3.8698780000 \\
\hline $\mathrm{H}$ & 2.8863970000 & -2.0034390000 & 4.0529920000 \\
\hline $\mathrm{H}$ & -1.7852990000 & -5.3664820000 & -0.9708530000 \\
\hline C & -0.7528190000 & -3.4726660000 & -0.8616990000 \\
\hline 0 & -0.1078430000 & -2.6026230000 & -1.5538150000 \\
\hline $\mathrm{N}$ & -0.3392400000 & -3.1495390000 & 3.8991820000 \\
\hline C & 0.8487820000 & -2.5114340000 & 4.5742330000 \\
\hline C & -1.6085540000 & -4.4880230000 & -1.5957910000 \\
\hline $\mathrm{H}$ & -2.5766750000 & -4.0278020000 & -1.8338760000 \\
\hline $\mathrm{H}$ & 1.0172720000 & -2.9257470000 & 5.5787230000 \\
\hline $\mathrm{H}$ & -1.2244580000 & -2.8733300000 & 4.3276600000 \\
\hline $\mathrm{H}$ & 0.6179560000 & -1.4436370000 & 4.6740380000 \\
\hline $\mathrm{H}$ & -1.1313710000 & -4.7681890000 & -2.5387480000 \\
\hline C & -3.3387600000 & -0.6047260000 & 3.6195260000 \\
\hline 0 & -2.8405200000 & -1.5126060000 & 4.2136990000 \\
\hline $\mathrm{O}$ & -3.8831230000 & 0.2971340000 & 3.0672820000 \\
\hline C & 1.7491120000 & -5.2329130000 & 1.3194880000 \\
\hline & & S1 & \\
\hline
\end{tabular}




\begin{tabular}{llll} 
O & 1.1809740000 & -5.5381630000 & 2.3248710000 \\
\hline & 2.3230620000 & -4.9943260000 & 0.3030870000
\end{tabular}

Table S9. Final atomic coordinates (in $\AA$ ) of the optimized $[\mathrm{Zn}]_{2}+\mathrm{CO}_{2}$.

\begin{tabular}{|c|c|c|c|}
\hline $\mathrm{O}$ & 0.2138410000 & -2.4001350000 & -0.3615390000 \\
\hline $\mathrm{H}$ & 2.8412910000 & -0.5584050000 & -2.7366060000 \\
\hline $\mathrm{H}$ & -1.1953590000 & -4.4434660000 & -0.8050240000 \\
\hline $\mathrm{H}$ & 4.8241210000 & -1.8573250000 & -2.1436810000 \\
\hline 0 & 3.4546270000 & -2.2626000000 & -0.5993280000 \\
\hline C & 4.3014510000 & -1.3395020000 & -1.3213920000 \\
\hline C & -1.0705910000 & -2.3210520000 & -0.4334790000 \\
\hline $\mathrm{H}$ & -2.4231470000 & -3.4601950000 & -1.6544050000 \\
\hline C & 3.4835810000 & -0.1702600000 & -1.9355920000 \\
\hline C & -1.8621710000 & -3.5835700000 & -0.7202440000 \\
\hline $\mathrm{Zn}$ & 1.8897180000 & -1.3303860000 & 0.1131180000 \\
\hline $\mathrm{H}$ & 4.1563880000 & 0.5844270000 & -2.3703060000 \\
\hline $\mathrm{H}$ & 1.7773350000 & 0.9692880000 & -1.2573330000 \\
\hline $\mathrm{N}$ & 2.5863730000 & 0.4175450000 & -0.8900890000 \\
\hline $\mathrm{H}$ & 5.0785730000 & -0.9118690000 & -0.6567650000 \\
\hline $\mathrm{H}$ & -2.5905950000 & -3.7535410000 & 0.0796120000 \\
\hline $\mathrm{O}$ & -1.7328660000 & -1.2088100000 & -0.2821340000 \\
\hline $\mathrm{H}$ & 3.1058280000 & 1.0085460000 & -0.2358980000 \\
\hline $\mathrm{H}$ & -0.5210340000 & 3.6073910000 & -1.7526400000 \\
\hline 0 & 0.1874470000 & 1.6832120000 & -1.2900350000 \\
\hline $\mathrm{Zn}$ & -1.0065080000 & 0.6784170000 & -0.0705790000 \\
\hline
\end{tabular}




\begin{tabular}{|c|c|c|c|}
\hline $\mathrm{C}$ & -0.5450650000 & 2.5793020000 & -2.1554410000 \\
\hline $\mathrm{O}$ & -0.3337560000 & 0.7399080000 & 1.8448600000 \\
\hline $\mathrm{H}$ & -2.7522960000 & 2.6977340000 & -0.4112880000 \\
\hline $\mathrm{H}$ & -0.0960110000 & 2.6060180000 & -3.1611800000 \\
\hline $\mathrm{H}$ & 0.1749980000 & 1.2795360000 & 4.2947460000 \\
\hline C & 0.5728540000 & 0.1051700000 & 2.5252750000 \\
\hline $\mathrm{O}$ & 1.4302890000 & -0.7076590000 & 2.0006010000 \\
\hline $\mathrm{N}$ & -2.5899750000 & 1.8379120000 & -0.9425890000 \\
\hline$C$ & -2.0228250000 & 2.1399250000 & -2.3034530000 \\
\hline $\mathrm{C}$ & 0.6098470000 & 0.3133060000 & 4.0284700000 \\
\hline $\mathrm{H}$ & 0.0183690000 & -0.4765690000 & 4.5103130000 \\
\hline $\mathrm{H}$ & -2.6056960000 & 2.9136020000 & -2.8219960000 \\
\hline $\mathrm{H}$ & -3.4633740000 & 1.3087380000 & -0.9903930000 \\
\hline $\mathrm{H}$ & -2.0782120000 & 1.2140240000 & -2.8882080000 \\
\hline $\mathrm{H}$ & 1.6358180000 & 0.2399310000 & 4.3987310000 \\
\hline$C$ & -4.6640110000 & -1.2760480000 & 0.2660580000 \\
\hline 0 & -4.7517230000 & -0.2630330000 & -0.3568050000 \\
\hline $\mathrm{O}$ & -4.6099530000 & -2.2860830000 & 0.8944340000 \\
\hline $\mathrm{C}$ & 1.0805760000 & 3.4259940000 & 0.8752140000 \\
\hline $\mathrm{O}$ & 0.0349840000 & 3.9991920000 & 0.8511380000 \\
\hline $\mathrm{O}$ & 2.1496170000 & 2.9014330000 & 0.9491060000 \\
\hline
\end{tabular}

Table S10. Final atomic coordinates (in $\AA$ ) of the optimized $[\mathrm{Zn}]_{2}+\mathrm{ME}+\mathrm{CO}_{2}$. 


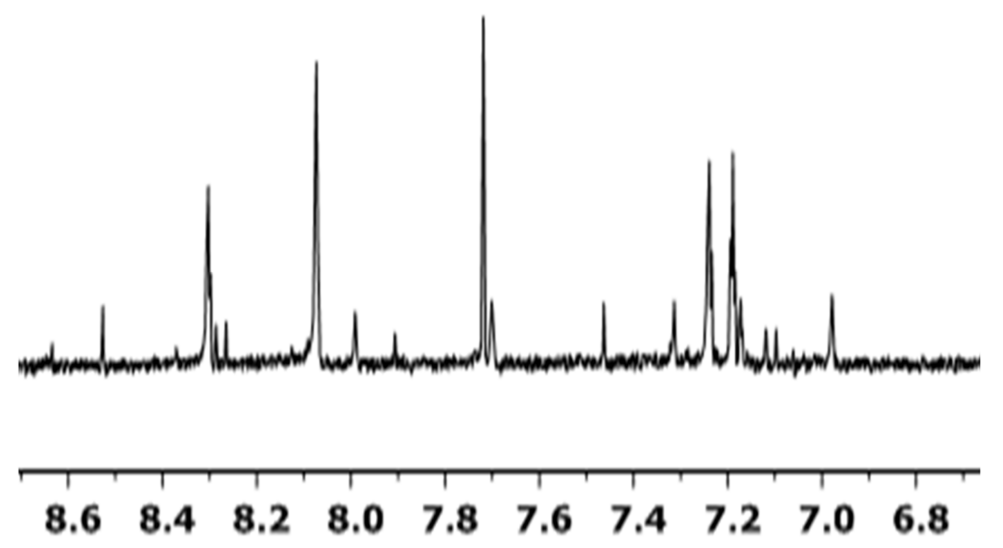

Fig. S1. Partial view of the ${ }^{1} \mathrm{H}-\mathrm{NMR}$ spectrum $(400 \mathrm{MHz})$ in the range $6.7<\delta<8.7 \mathrm{ppm}$ of the sample containing $E A+M E$ after 8 weeks exposed to light and air.

Complete reference ${ }^{25}$ :

Frisch, M. J.; Trucks, G. W.; Schlegel, H. B.; Scuseria, G. E.; Robb, M. A.; Cheeseman, J. R.; Montgomery, Jr., J. A.; Vreven, T.; Kudin, K. N.; Burant, J. C.; Millam, J. M.; Iyengar, S. S.; Tomasi, J.; Barone, V.; Mennucci, B.; Cossi, M.; Scalmani, G.; Rega, N.; Petersson, G. A.; Nakatsuji, H.; Hada, M.; Ehara, M.; Toyota, K.; Fukuda, R.; Hasegawa, J.; Ishida, M.; Nakajima, T.; Honda, Y.; Kitao, O.; Nakai, H.; Klene, M.; Li, X.; Knox, J. E.; Hratchian, H. P.; Cross, J. B.; Bakken, V.; Adamo, C.; Jaramillo, J.; Gomperts, R.; Stratmann, R. E.; Yazyev, O.; Austin, A. J.; Cammi, R.; Pomelli, C.; Ochterski, J. W.; Ayala, P. Y.; Morokuma, K.; Voth, G. A.; Salvador, P.; Dannenberg, J. J.; Zakrzewski, V. G.; Dapprich, S.; Daniels, A. D.; Strain, M. C.; Farkas, O.; Malick, D. K.; Rabuck, A. D.; Raghavachari, K.; Foresman, J. B.; Ortiz, J. V.; Cui, Q.; Baboul, A. G.; Clifford, S.; Cioslowski, J.; Stefanov, B. B.; Liu, G.; Liashenko, A.; Piskorz, P.; Komaromi, I.; Martin, R. L.; Fox, D. J.; Keith, T.; Al-Laham, M. A.; Peng, C. Y.; Nanayakkara, A.; Challacombe, M.; Gill, P. M. W.; Johnson, B.; Chen, W.; Wong, M. W.; Gonzalez, C.; Pople, J. A. (2004). “Gaussian 03, Revision C.02", Gaussian, Inc., Wallingford CT. 